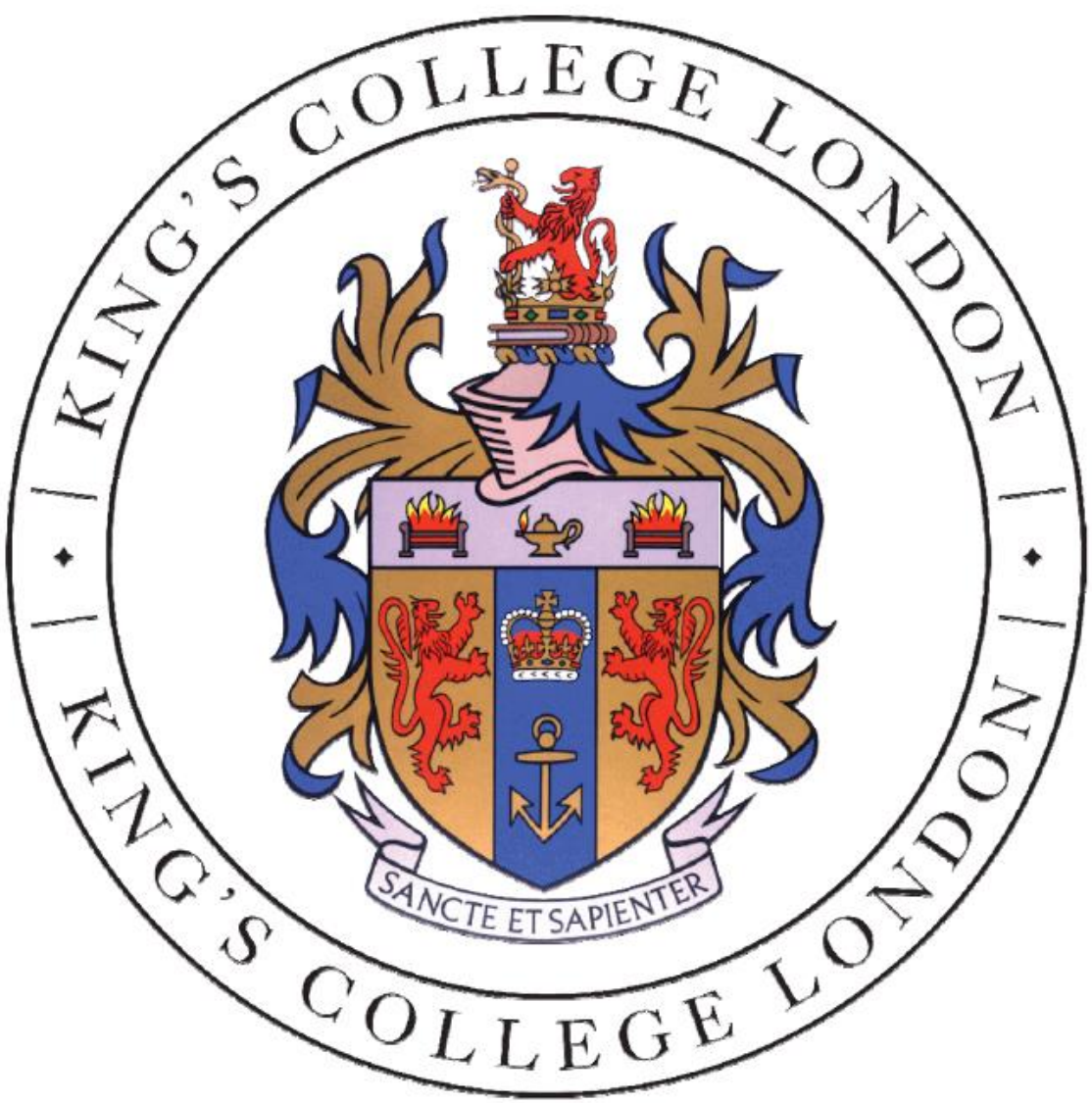

\title{
The Effects of Social Rewards on Incidental Episodic Memory
}

\author{
Gaia Molinaro \\ BSc Neuroscience \\ Department of Neuroscience Education \\ King's College London \\ April 2020
}

Supervised by Dr Charlotte Russell

Institute of Psychiatry, Psychology \& Neuroscience 


\section{Acknowledgements}

I would like to thank Dr Charlotte Russell for giving me the opportunity to work under her supervision and offering her lab's resources for my project. I would also like to thank Dr Isabella Gavazzi for organizing the "Laboratory Research Project in Neuroscience" module, even more so in light of the unexpected circumstances in which the last part of this semester was carried out. 


\section{Table of Contents}

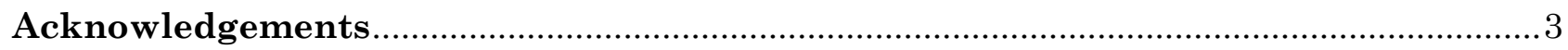

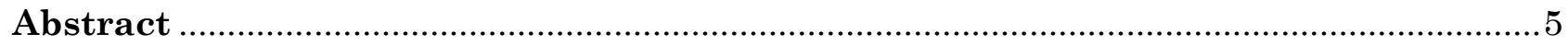

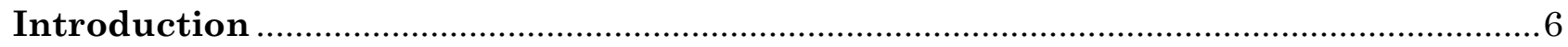

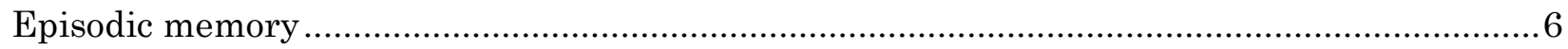

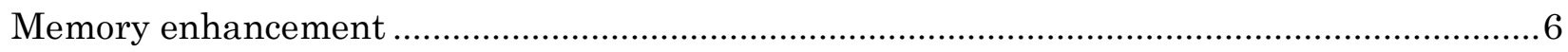

Studying incidental learning through social rewards .................................................... 7

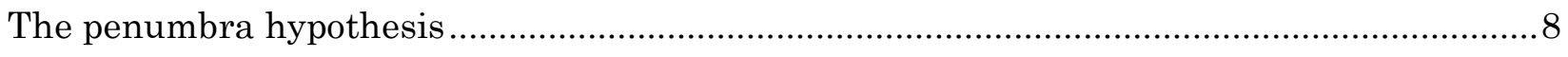

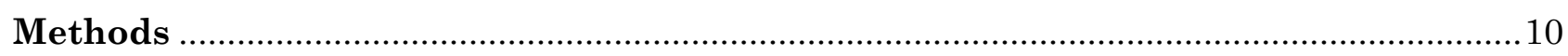

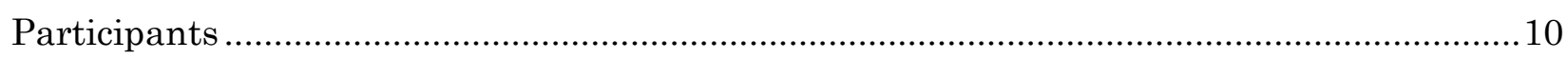

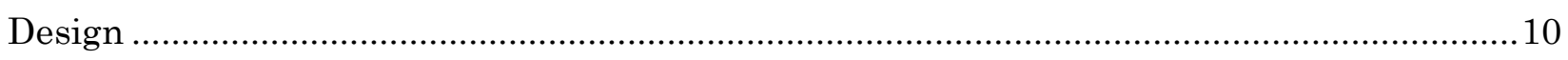

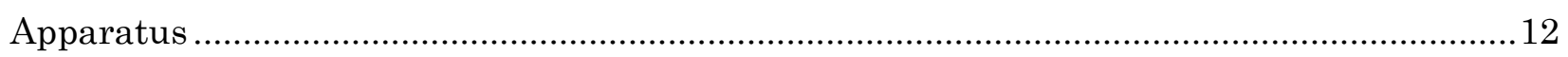

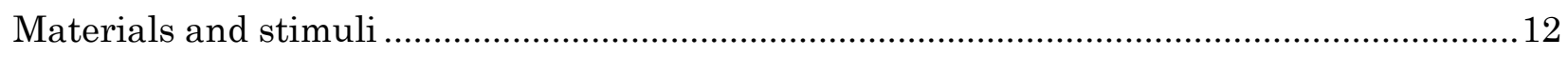

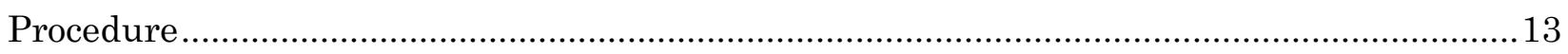

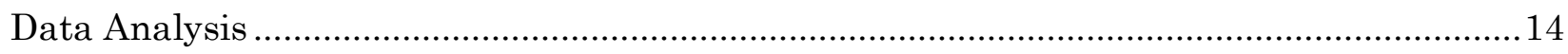

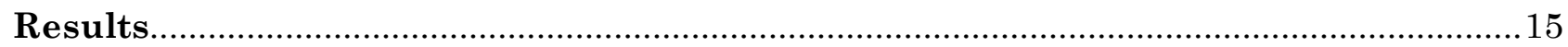

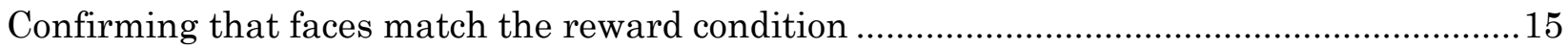

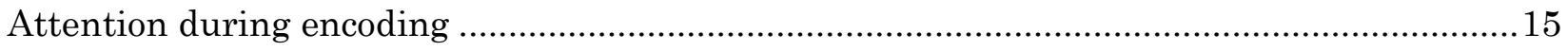

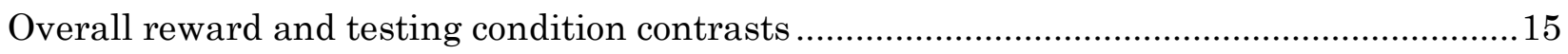

Mood-based reward condition contrasts ....................................................................... 17

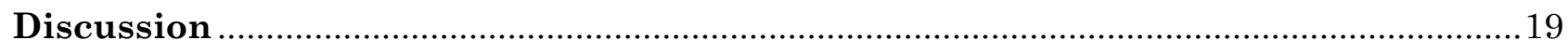

Potential primacy of space relative to time in episodic memory …...................................... 19

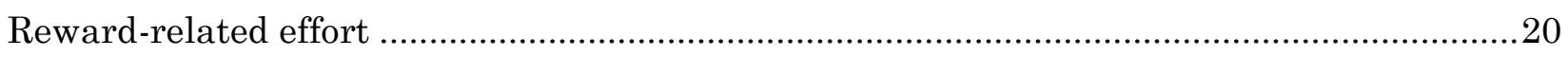

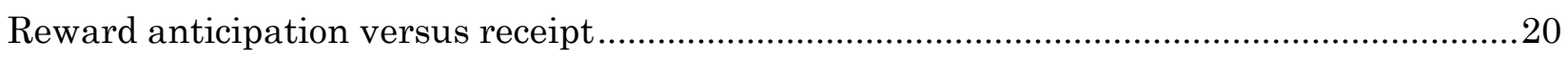

Neutral as negative and the inconsistent effects of arousal ............................................21

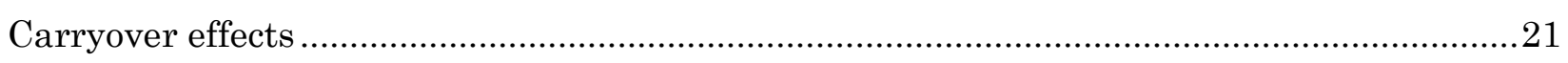

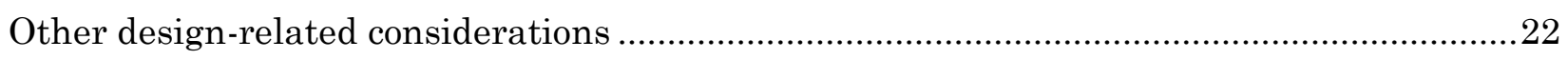

The effects of mood on socially relevant decisions and memory .........................................22

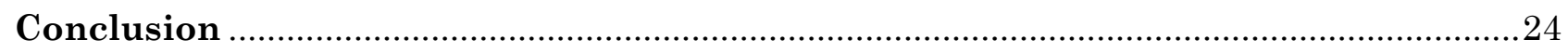

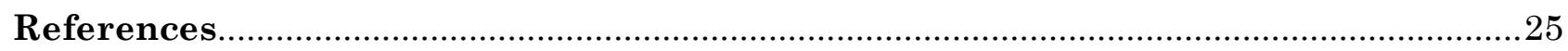




\begin{abstract}
Episodic memory is our memory for specific, personally experienced events. Although remembering the "what, where and when" of an instance may be highly beneficial, the brain's memory capacity is limited and must therefore be selective. Rewards are important enhancers of episodic memory acquisition and storage. Among them, social rewards have been proposed as important drivers of motivated behaviour. Whether the benefits of social rewards on memory still operate on incidental (unplanned) memorization of neutral events has not been tested yet. In this study, we explored the effects of social rewards on memory for neutral scenes that were completely unrelated, except for proximity in time, to the sources of reward (here, the presentation of happy versus neutral faces). One day after the completion of an encoding task, participants were given a surprise memory test that assessed their recollection of spatial or temporal information related to such incidental scenes. Differences in memory for space versus time-related information were observed. Although participants were expected to have better memory for scenes that occurred after delivery of social rewards, this was not the case; possible explanations for this are discussed. However, strong interactions between the anticipated effect and participants' mood were noted, and our initial hypothesis did hold true in a subset of participants who experienced exceptionally low mood on the day of encoding. These findings hint at the limitations of a reward-driven enhancement of incidental episodic memory and highlight the important role of mood in modulating the extent of such an effect.
\end{abstract}




\section{Introduction}

\section{Episodic memory}

Episodic memory is memory for personally experienced events that occurred in particular places at particular times. In other words, episodic memory is about the "what, where and when" of specific instances (Tulving, 2002). It is our private collection of representations of the world, whose rules are hence internalized by accumulating examples of how it normally works. Episodic memory provides a framework for new ones. It allows us to make predictions about the future and decisions in the present, to interpret the past and communicate it to others (Mahr and Csibra, 2018). Some also emphasize its role in imagining and predicting future scenarios (Tulving, 2005; Dudai and Carruthers, 2005). The contributions of episodic memory, as a source of specific samples, to behavioural and decisional control - compared to those of semantic memory as a storage for statistical inferences - has also been stressed through computational methods (Lengyel and Dayan, 2008; Gershman and Daw, 2017). However, brains have a limited memory capacity; thus, the selective inclusion of information in memory storage is crucial for adaptive functioning.

\section{Memory enhancement}

Indeed, memory formation and recall are more efficient for events that are immediately or even distantly related to highly emotional states (Todd et al., 2012; Tambini et al., 2017). This emotion-driven modulation of memory seems to operate both prospectively and retroactively, i.e. it may enhance memory for events happening either before or after the onset of the emotional experience (Dunsmoor et al. 2015). At the same time, attention during encoding predicts the strength of both intentional and incidental (i.e., unplanned) learning (Chun and Turk-Browne, 2007). In turn, stimuli that have been previously associated with rewards automatically capture attention (Della Libera and Chelazzi, 2009; Hickey et al. 2011; Anderson et al., 2014) and are better remembered (Wittmann et al., 2005; Adcock et al., 2006; Callan and Schweighofer, 2008). This is also applicable to episodic memory consolidation for both explicitly (Wittmann et al., 2011) and incidentally encoded stimulus features (Mason et al., 2019). Prioritizing memory for events that occurred close to the receipt of a reward helps to replicate those instances in the future.

Early psychologists noted how learning and behaviour are largely guided by rewarding outcomes ("reinforcers"; Thorndike, 1898; Skinner, 1938). More recently, neuroscientists have started looking at how limited memory capacity is selectively directed to factual or believed sources of rewarding instances so that their occurrence can be replicated. In fact, memory can be driven by either intrinsic or extrinsic motivation. The former refers to an activity being performed because its execution is inherently satisfying, while the latter is encouraged by external incentives. On the one hand, intrinsic motivation might be the most powerful drive for learning (Deci and Ryan, 2012). Epistemic curiosity modulates neural activity in brain areas related to both reward processing and memory (Kang et al., 2009; Marvin and Shohamy, 2016; Sharot and Sunstein, 2020). Remarkably, Gruber and colleagues (2014) found that curiosity enhances memory not only for the kind of information that triggers it, but also for task-irrelevant material (in their case, human faces) that is presented while one is in a highcuriosity state. Extrinsic motivation, on the other hand, may be promoted by both primary (required for survival) or secondary (higher-order) reinforcers. Financial benefits have been studied the most, but recent evidence suggests that social rewards guide attention (Anderson, 
2016; Hayward et al., 2018) and behaviour (Walter et al. 2005; Fehr and Camerer, 2007) in a similar way and perhaps through the same neural circuits as monetary incentives (Behrens et al., 2008; Izuma et al., 2008; Gu et al., 2019; but see Linke et al., 2010; Lee et al., 2012; Lee and Reeve, 2013). Among other kinds of cues, memory enhancement can be directed by social interactions and stimuli, from one's parents' smiles and frowns, to one's boss's praise or rebuke at work. Social cues as simple as genuine smiles can carry high inherent value and influence people's behaviour (Shore and Heerey, 2011), and some facial expressions endorse memory for information related to them (Sergerie et al. 2007; Tsukiura and Cabeza, 2008). However, the effects of social rewards on incidentally encoded episodic-like memory have not yet been defined.

\section{Studying incidental learning through social rewards}

Humans are social animals, optimized for living in groups and relying on others. Indeed, little would humans have progressed without interacting with their conspecials (Harari, 2014). In turn, some suggest that the complexity of primate brains is the result of a need for more efficient acquisition and manipulation of social information (Dunbar, 1998). It has long been known that the presence of others influences individual performance (Zajonc, 1965). More recently, the rewarding nature of social interactions - ranging from simple stimuli to involvement in more complex situations - has gained attention from the neuroscientific community (Mayes et al., 2009; Krach et al., 2010), together with the role of social cues in learning (Kringelbach and Rolls, 2003), where they might even be preferred to non-social feedback (Shore and Heerey, 2011). Human faces are commonly found in the literature as material for paradigms that investigate social reward and neural responses to stimuli that carry an emotional charge (e.g., Knutson, 1996; Morris et al., 1996; Kampe et al., 2001; O'Doherty et al., 2003; Johnston et al., 2010; Heerey, 2014). Based on their efficacy as social reinforcers attested by previous research (for instance, see Spreckelmeyer et al., 2009, and Shore and Heerey, 2011), smiling faces were used in this study to model the effects of social reward on episodic memory, compared to neutral expressions.

Motivated learning has been extensively studied (for a review, see Miendlarzewska et al., 2016). However, relationships between rewards and their sources may sometimes only become evident in retrospect; thus, at least initially, it might be important to enhance memory for events that occurred around reward consumption with relatively little bias for their relevance. Incidental learning is learning that was neither intentionally motivated by an individual, nor explicitly reinforced by external rewards. In experimental settings, it is usually measured through surprise memory tests, whereby participants are typically asked to recognize images of previously seen objects and state when they detect new ones. In this way, it is possible to measure the effects of rewards on memory without the confounding elements of selective attention and motivation (Murayama and Kitagami, 2013). Enhancement of incidental learning has been observed in experiments whereby rewards were semantically linked to an innocuous stimulus (Wittmann et al., 2011). As for completely unrelated material, one laboratory observed memory enhancement for faces of strangers that simply happened to be presented between expectation and delivery of reward (Gruber et al., 2014). However, the human brain is highly specialized for face processing (McKone et al., 2007): it only takes 100200 milliseconds to recognise a face (Liu et al. 2002). Thus, Murayama and Kitagami (2013) showed that rewards can also (retroactively) enhance memory for common objects. Nonetheless, memory enhancement for purely incidental material has not been tested yet for 
more complex events involving episodic-like memories of a certain event happening at a certain place and time.

The experiment described here is the first attempt to explore the influences of social rewards on incidental episodic memory. Specifically, the target features were the location and order of appearance of pairs of neutral (that is, neither rewarding nor predictive of a reward) images placed within an empty grid, aiming to model memory relative to the "where" and "when" of an event. Human participants took part in our experiment, during which they completed a computer-based task involving social reward delivery (in the form of happy versus neutral faces) and information encoding, and a surprise memory test.

As mood affects neural activity related to reward (Young and Nusslock, 2016) facial expression processing (Coupland et al., 2004; Schmid and Mast, 2010; Adams et al., 2016), and selective attention towards positive stimuli (Gable and Harmon-Jones 2008), the participants' positive and negative affect on the day of memory acquisition was measured and included in the analyses.

Although Gruber et al. (2014) observed curiosity-mediated enhancements in memory for incidentally encoded information both immediately after acquisition and the following day, multiple experiments have found emotional arousal or reward to enhance memory after a delay, but not in tests taken immediately after the encoding trials (Murayama and Kuhbandner, 2011; Sharot and Phelps, 2004; Murayama and Kitagami, 2013; Spaniol et al. 2014; Cohen et al., 2015). Based on these findings, the well-established role of sleep in memory consolidation (Rasch and Born, 2013; Stickgold and Walker, 2013), and the possibility that rewards facilitate off-line neuronal activity replay during sleep for stimuli that were associated with them (Lansink et al., 2009; Singer and Frank, 2009), participants' memory was assessed one day after the initial task completion.

We expected people to have better episodic-like memory for stimuli that appeared after they viewed smiling faces (i.e. after receiving a social reward), compared to neutral ones. Yet, some have found arousing stimuli to be distracting and thus disadvantageous for memory (reviewed in Mather and Sutherland, 2011).

\section{The penumbra hypothesis}

At the level of brain network interactions, reinforcement-induced memory enhancement could be supported by the reward system through connections with the hippocampus; these would detect rewarding, relevant or salient information and improve its encoding and consolidation in memory structures (Lisman and Grace, 2005). Enhanced activity in both the brain reward system and the hippocampus during the acquisition of new information is predictive of memory performance (Wittmann et al., 2005; Adcock et al., 2006). In fact, increasing evidence suggests that the hippocampus functions as an integration site whereby memory formation is modulated by the motivation to learn (Kennedy and Shapiro, 2009; Baudonnat et al., 2013).

This neurobiological framework has been first introduced by Lisman et al. (2011) and termed the "penumbra hypothesis" (exemplified in figure 1 below). Long-term potentiation (LTP) is the main neural correlate of memory (Bliss and Collingridge, 1993) and supports the Hebb rule of how synapses might code and store information (Hebb, 1949). Although localizationist theories have long been refuted (Lashley, 1950), the hippocampus remains a key neural substrate for memory, in general, and episodic memory, in particular (Squire and ZolaMorgan, 1991; Stark and Squire, 2003; Broadbent et al., 2004). According to Lisman and colleagues, at least some aspects of hippocampal LTP require external dopaminergic input from the midbrain in order to be fully implemented. Dopamine is released in subcortical 
regions tonically (i.e., as background activity) and phasically (i.e. transiently, in bursts; Grace, 1991). Both kinds of transmission could affect encoding and consolidation by marking events and associations that are particularly salient, novel, relevant for action, aversive or, more pertinently here, rewarding. Specifically, in familiar situations, tonic activity is relatively low; as a consequence, phasic release is also reduced; however, when the context is salient, new, or unpredictable, tonic activity increases, leading to strong dopaminergic bursts when a prediction error is signalled (Lisman et al., 2011). Notable stimuli might thus open a temporal window during which memory acquisition for proximate stimuli - whether they are relevant or not - can also be enhanced via this so-called "penumbra effect". Supporting evidence for the penumbra hypothesis comes from animal models (Huang and Kandel, 1995; Sajikumar and Frey, 2004; Lemon and Manahan-Vaughan, 2006), behavioural (see, for instance, Fenker et al., 2008), and neuroimaging studies (Krebs et al., 2011; Gruber et al., 2014; but see Kim, 2013 for other relevant brain areas). However, findings for extrinsic rewards are controversial: for instance, Wittman and colleagues (2011), report that reward - unlike novelty - only benefits memory for items that are somehow semantically related to it. Inconsistency across results may be due to differences in how dopaminergic inputs are triggered in different experiments. To our knowledge, the present study represents the first test for penumbra effects using social rewards and incidental episodic memory acquisition.

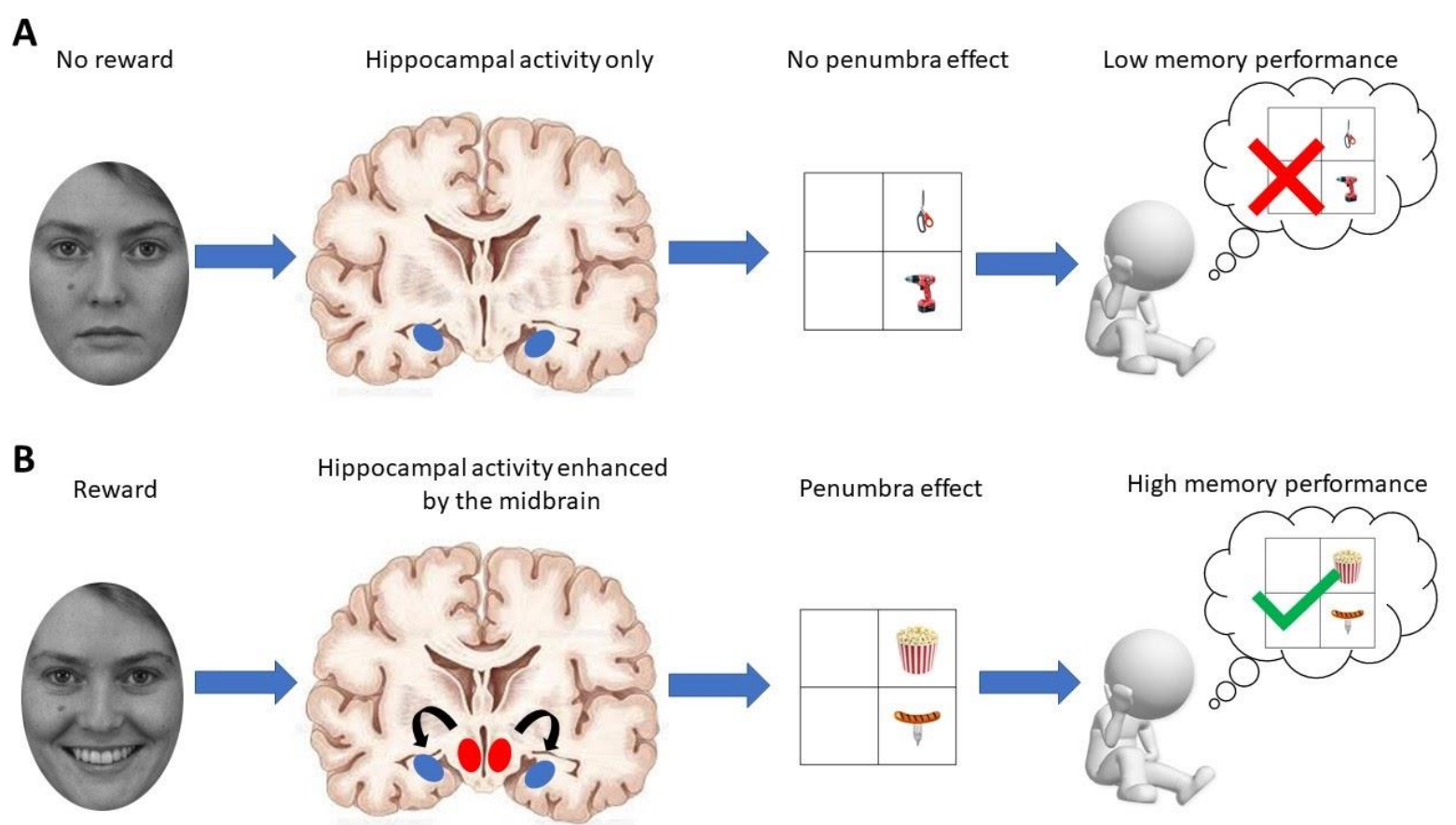

Figure 1. The "penumbra hypothesis" framework for the effects of social rewards on incidental episodic memory. In (A), processes hypothesized to take place in the no-reward condition are illustrated: presentation of a neutral face leaves hippocampal activity unaffected; when an event is presented incidentally, no memory enhancement mechanism favours its encoding or consolidation, resulting in poor memory performance. On the other hand (B), when a smiling face appears (in the reward condition), areas of the midbrain (in red) supposedly enhance the activity of the hippocampus (in blue), so that when an event is presented incidentally the penumbra effect contributes to its memorization. This ultimately results in better recollection during the surprise memory test. [Copyright-protected sources of the images used for this figure: Lundqvist (1998); Oto, E. (n.d.)] 


\section{Methods}

\section{Participants}

Forty-nine participants were recruited through the King's College London research recruitment bulletin and posters placed around campus. Three participants were excluded from the analyses: one did not show up for the second part of the experiment, another one scored too low on the "attention-check step" during the encoding task, and the third one misunderstood the memory test procedures. Results are hence based on the remaining fortysix participants. Thirty-seven of such participants were females, nine of them were males. The overall mean age was 21.7 years old (range: 18-35). All subjects had normal or normal-tocorrected vision and no diagnosis of psychiatric or neurological illnesses at the time of the study. A Research Ethics Minimal Risk Self-Registration Form was submitted and confirmed by the King's College London Research Ethics Office, with the code: MRA-19/20-17317. Subjects gave written informed consent to participate in a study on "face processing and cognitive tasks" and received a $£ 15$ compensation for their total time spent on the experiment. Upon completion, they were informed on our hypothesis as part of the debriefing process.

\section{Design}

After receiving instructions, participants began the first section of the experiment by completing a questionnaire to assess their mood as positive and negative affect scores. Then, they started the encoding task proper (figure 2). Either a neutral or a happy person's face appeared in each trial, determining the encoding condition (i.e. no-reward versus reward). Participants judged how friendly the person looked to them based on that image. This was followed by the presentation of an empty grid on which a pair of neutral objects appeared, in sequence and in different locations, which modelled the incidental, episodic-like event. To ensure high attention levels throughout the trial, participants had to answer a question related to the incidental event; these questions were not related to the information that was later tested. Then, the same face was presented again and followed by another friendliness judgement. Note that this latter step was mainly included to match another experiment that was concurrently run within our lab and allow for comparisons between the two in the future. Faces and the associated grids appeared in random order, 8 per block for a total of 12 blocks (hence, 96 trials). Correlations between faces and grids were counterbalanced through pseudorandomization as three different sheets were created for the encoding phase's script and randomly assigned to participants.

The follow-up surprise memory test (figure 3) consisted of a "same/different" task in which participants were shown the incidental scenes and had to decide whether they had seen exactly the same scene before or not. In fact, while the images presented in the grid squares and their pairs never changed, to some of the grids either a spatial or a temporal manipulation was applied. For one condition (spatial manipulation), the location of the images within the grids was different in one-third of the cases. For the other condition (temporal manipulation), the same grids changed in that the order in which pictures appeared on them was reversed, while relative locations remained unaffected. 96 grids and questions appeared, 8 per block for a total of 12 blocks. The two testing conditions represented different branches of the testing part, of which each participant only completed one. These were randomly assigned. After data from the first 7 participants were collected, we decided to also counterbalance which grids changed and which ones stayed the same through pseudorandomization; from 
then on, three different sheets were used for the testing phase script and randomly assigned to participants.

A

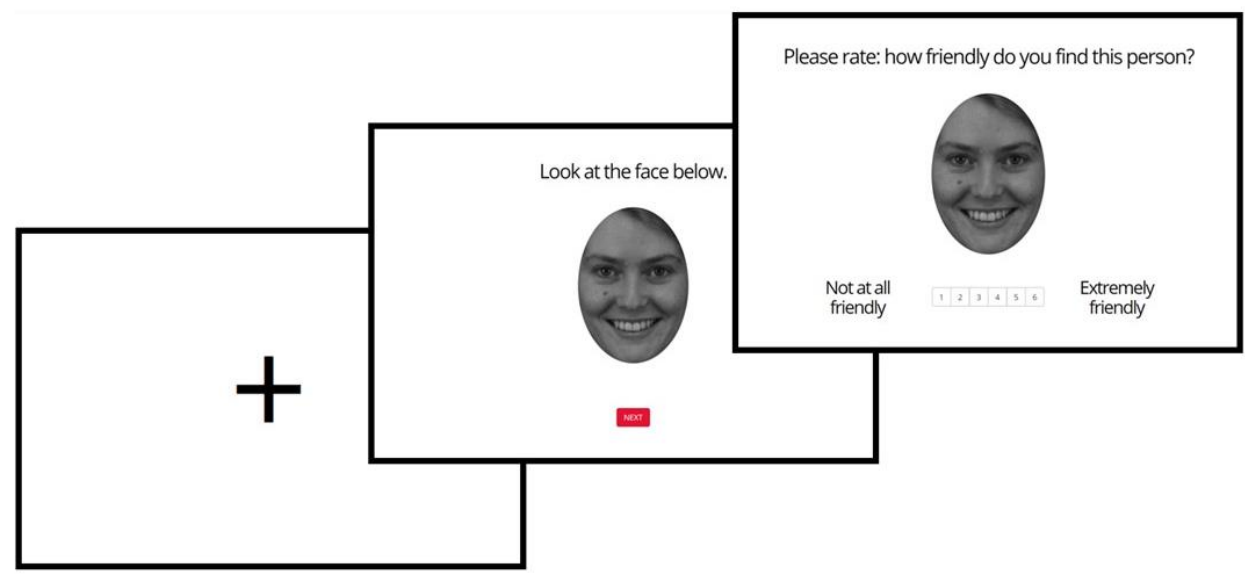

$2000 \mathrm{~ms}$

B

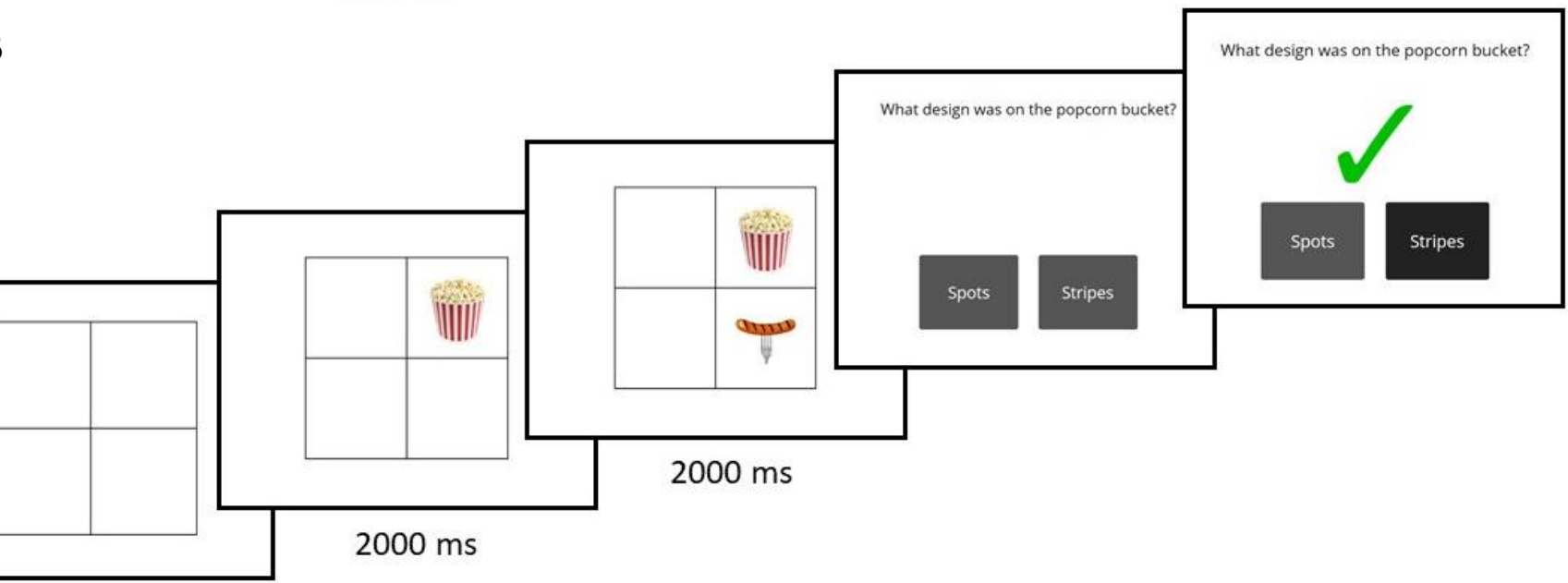

$2000 \mathrm{~ms}$

C

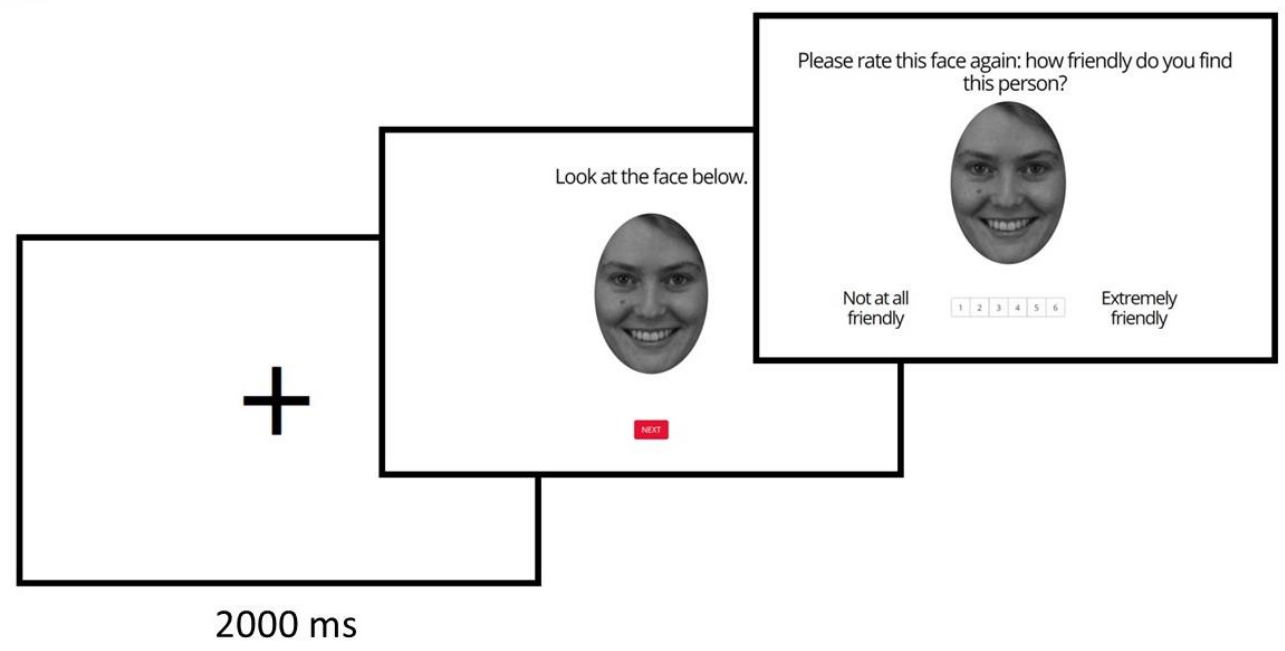

Figure 2. Encoding task. On each trial, participants were asked to rate a person's face, either with a smiling or neutral expression, based on how friendly they found them (A) ["Please rate: how friendly do you find this person?" Options: 1-6, with 1 = "Not at all friendly", $6=$ "Extremely friendly"]. Next, they viewed a grid on which a pair of objects appeared in a specific sequence and location; participants were then asked a question on a detail relating to one of the two objects that appeared on the grid [e.g. here, "What design was on the popcorn bucket?" Options: "Spots", "Stripes"] and received visual feedback upon responding (B). Finally, participants were asked to make the same judgement on the face that they had just viewed (C) ["Please rate this face again: how friendly do you find this person?" Options: 1-6, with $1=$ "Not at all friendly", 6 = "Extremely friendly"]. 

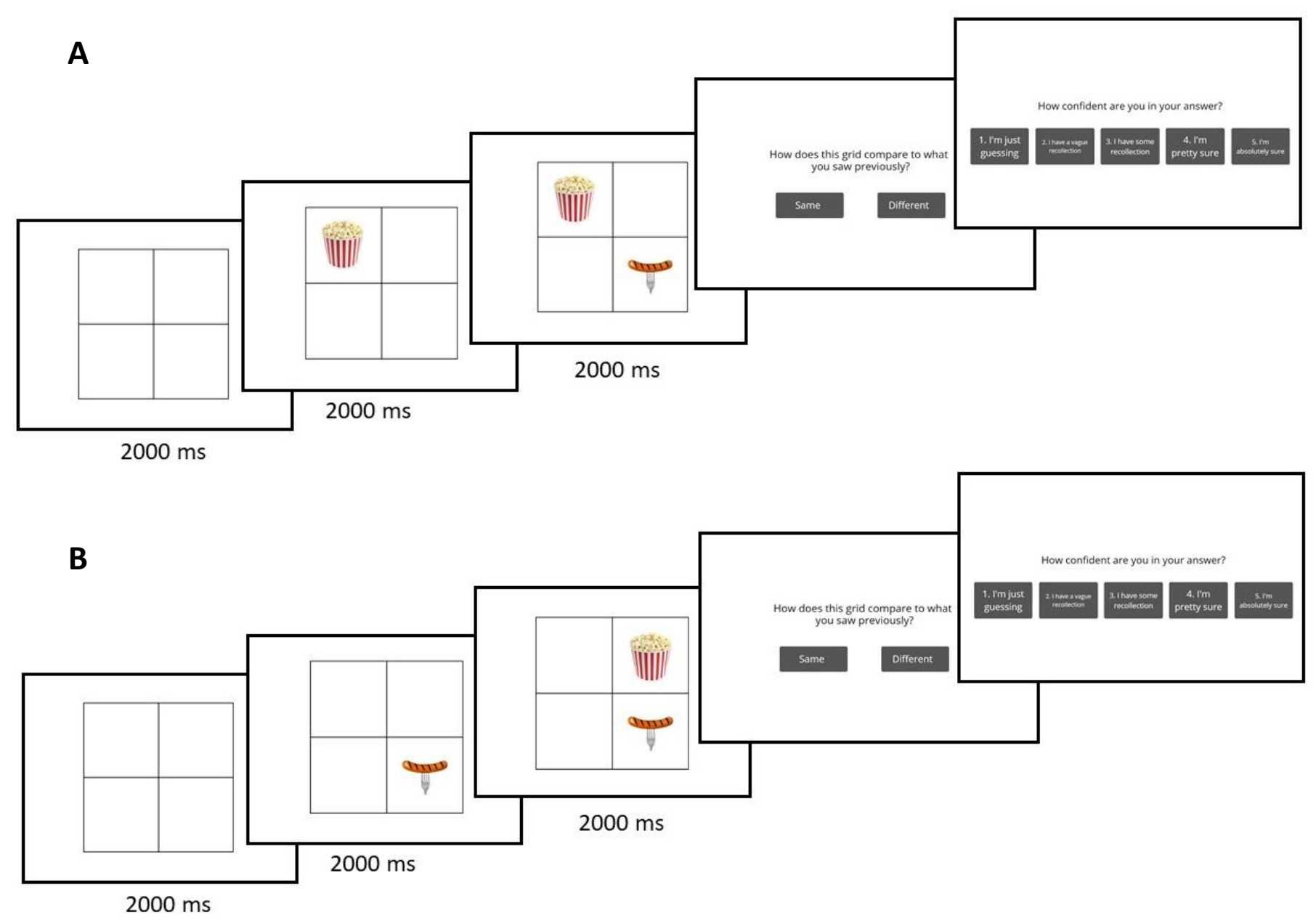

Figure 3. Memory test. On the second day of the experiment, participants were shown grids from the encoding task, some of which were different in that either the location of one of the objects (A: note how the popcorn bucket is now on the top left corner instead of the top-right) or their appearance (B: note how the hot dog now appears before the popcorn bucket) changed from the original. Participants were then asked to state whether they thought each grid was identical to or different from the one they saw the previous day. ["How does this grid compare to what you saw previously?" Options: "Same", "Different"]. They were also asked how confident they were about their answer. ["How confident are you in your answer?" Options: "1. I'm just guessing", "2. I have a vague recollection", "3. I have some recollection", "4. I'm pretty sure", "5. I'm absolutely sure"]. Note that each participant was randomly assigned to only one manipulation and that only one-third of the grids were manipulated.

\section{Apparatus}

A Dell OptiPlex 9030 computer was used to present the stimuli and provide an interface for answer registration. Responses were entered by selecting buttons on the display through a mouse. Subjects viewed the screen from a distance of approximately $60 \mathrm{~cm}$ and sat in a quiet, dimly lit room. The Gorilla Experiment Builder (www.gorilla.sc) online platform was used to create and host the experiment (Anwyl-Irvine et al., 2020).

\section{Materials and stimuli}

Mood questionnaire. The Positive and Negative Affect Schedule (PANAS; Watson et al., 1988) was used to measure mood. The PANAS is structured as two 10-item scales. Each item (e.g. "excited" for the positive, "irritable" for the negative affect scale) is rated 1-5 based on the extent to which one agrees to feel in the way described by it ( $1=$ "Not at all", $5=$ "Very much") at the time of filling out the questionnaire. Scores for each item are added up within their category to yield a total score (ranging from 10 to 50) for positive and for negative affect; note that the two are calculated separately and do not necessarily correlate. 
Faces. A total of 96 pictures of human faces, half neutral and half smiling, were used in the experiment. 48 of such images (24 per kind) were taken from material used in a previous experiment run in our laboratory. These had been obtained from the Karolinska Directed Emotional Faces (KDEF; www.kdef.se, Lundqvist et al., 1998) and Face Research Lab London Set databases (www.figshare.com; DeBruine and Jones, 2017). To prevent participants from being biased by extrinsic attributes, each image was cropped of hair and background, and converted into grayscale using the Gnu Image Manipulation Program (GIMP 2.10.18, www.gimp.org). They were also rated for attractiveness (neutral faces) or how rewarding the smile was (smiling faces) both within and outside of the laboratory - the latter through Qualtrics (www.qualtrics.com). 48 new faces were added to the present experiment; these were taken from the same databases and adapted to fit the old images' features. They were also rated by the experimenter and the supervisor independently, and faces that were not unanimously selected were discarded and substituted. Whenever possible, pictures were paired so that each neutral face had a corresponding smiling face portrayed from the same individual; this eliminated potentially confounding effects due to differences in face distinctiveness (Valentine, 1991). For examples, see the images of faces used in figure 1.

Grids. An empty $2 \times 2$ grid was displayed in each trial of both the encoding and the testing task. A picture of an inanimate object or animal was presented in one of the grid's squares, followed by a second picture from the same category on a different square. Images belonged to one of 12 categories, e.g. sporting goods, kitchen tools, or food, with 16 images per category (128 in total, 2 per grid). In the encoding task, each grid was also associated with a question about the images that appeared in it; such questions were always related to one of the object's physical features (a detail such as "How many lemons were there?", or "Did the sushi have seaweed on it?"), but not to its location or order of appearance. All the grids and respective images used for the encoding phase (but not the related questions) were included in the second part of the experiment. Grids, respective images, questions, and answer options used here were taken from material previously used within our lab.

All stimuli appeared on a white background in the centre of the screen.

\section{Procedure}

Encoding task. Before the experiment started, participants completed a questionnaire to rate their mood. Then, in each trial (figure 2), participants viewed a black fixation cross in the centre of the screen for $2000 \mathrm{~ms}$. Next, one of the faces was displayed along with instructions for participants to look at it. Upon clicking the "Next" button, a Likert scale appeared below the face image and participants were asked to rate how friendly they found that person (with extremes being 1 = "Not at all friendly", 6 = "Extremely friendly"). After subjects gave their rating, an empty grid was displayed. After $2000 \mathrm{~ms}$, a picture of an inanimate object or animal was presented in one of the grid's squares, followed after $2000 \mathrm{~ms}$ by a second picture from the same category on a different square. Grids and relative images appeared for a total time of $6000 \mathrm{~ms}$. Next, participants were asked a question about the images that had just appeared and had to respond through a two-options forced choice, one of which was correct. Participants received feedback on their answer. They then viewed the face-rating display again and had to make a judgement on the same face again. Finally, participants could proceed onto the next trial by clicking a button. They were allowed to take a short break at the end of every block if they wished to do so. There was no time limit for any of the ratings or choices, and participants took approximately 35 minutes to complete this part of the experiment.

Memory test. All participants were instructed to come to our testing room twice (on two consecutive days). They were told that the second day would be for a follow-up on the first 
experimental session, but they were not given further specifications. In fact, a surprise memory test was given on day two of the experiment. In each trial (figure 3), participants had to determine whether the grids that they viewed were identical in all features to those that they had seen the day before. After viewing a fixation cross, a grid appeared with respective images (as explained above for the encoding part). A binary choice screen was then displayed to have participants decide whether they had seen exactly the same grid while going completing the encoding task. They then had to rate their confidence on a scale from 1 to 5 (where the extremes were $1=$ "I'm just guessing" and $5=$ "I'm absolutely sure"), after which they clicked a button to proceed onto the next trial without receiving feedback. There was no time limit for any of the choices. The average time spent on the memory test was approximately 25 minutes.

\section{Data Analysis}

Answers to questions that were asked during the encoding task, i.e. questions on a detail of one of the images that had just appeared on the grid for a given trial, were used to determine the attention level of participants during the presentation of incidental events. To test our main hypothesis, mixed-effects ANOVA tests were carried out with within-subjects conditions being based on whether events were associated with smiling or neutral faces, and betweensubjects tests based on the testing condition (either temporal or spatial). Independent t-tests were carried out to interrogate differences between testing conditions. Paired t-tests were run to analyse differences between the neutral and the smiling encoding condition within each group. The main outcome measures were $d$ ' ("dee prime") values - a measure of how sensitive participants were at discriminating changed scenes from original ones. In order to compute $d$ ' values, hit and false alarm rates were converted to z-scores and subtracted; when hit and false alarm rates were either at $100 \%$ or $0 \%$, their conversion was calculated by imposing $(\mathrm{N})-1 / \mathrm{N}$ and $1 /\left(\mathrm{N}^{*} 2\right)$ values, respectively, $\mathrm{N}$ being the total number of either "yes" (or "same", i.e. the grid was identical to the one previously seen) or "no" (or "different", i.e. the grid had been manipulated) trials. Using $d$ ' in the analyses, instead of simply calculating the percentage of correct answers in the memory test, allows for response bias to be taken into account: in fact, during the discrimination task, individual participants might have been more or less conservative when they were unsure about what the correct answer would be. Reaction times for participants' performance and their confidence levels during the memory test were also measured. In addition, the effects of, and correlations with, participants' mood were also taken into account. For correlation analyses, this was done by using positive and negative affect scores directly. In order to interrogate the data based on low versus high positive or negative affect, rather than the condition used in the memory test, participants were also split into groups based on their PANAS scores. As there is no predefined cut-off in the PANAS, group membership was assigned according to whether each participant's scores were above, or equal to and below, the median for each affect-scale category (as in Norlander et al., 2002). Each participant could belong to any combination of the following groups: high or low positive affect, and high or low negative affect. 


\section{Results}

\section{Confirming that faces match the reward condition}

Individual ratings for neutral and smiling faces correlated with the intended condition, and the mean score for the first rating of faces in the "neutral" condition $(M=2.38, S D=.59)$ and the "smiling" condition $(M=4.49, S D=.67)$ were significantly different, $t(45)=-14.57, p<$ .001. Therefore, neutral versus smiling sets of faces were used to define within-group contrasts in all further analyses. Participants slightly increased their friendliness ratings for the neutral (but not the smiling) faces after viewing the grids and answering questions about the objects in them, and this was on the threshold for being correlated with their attention scores during encoding, $r(45)=.290, p=.050$. Thus, there might be an effect of positive, nonsocial feedback on the evaluation of neutral facial expressions. An effect of familiarity is also plausible. In the following analyses, only the first evaluation on perceived friendliness that participants made was taken into account.

\section{Attention during encoding}

Answers to questions that were asked during the encoding task were used to check participants' attention levels during the experiment. One participant scored less than $70 \%$ in the "attention-check" questions and was hence removed from all further analyses. The mean attention scores (in percentage) for the remaining 46 participants were $M=87.11, S D=3.31$. There was a significant difference in the number of correct answers, $t(45)=3.193, p=.003$, depending on whether they did or did not follow a social reward. Mean attention scores (out of 46 , in percentage) were $M=92.16, S D=3.73$, and $M=89.31, S D=5.32$ for grids associated with neutral and smiling faces, respectively. Albeit small (less than one standard deviation separates the two means), this difference suggests that, on average, participants were paying less attention to events that occurred after the appearance of smiling faces, compared to neutral ones. These effects did not correlate with PANAS scores and were thus independent of mood at the time of task completion. With this in mind, all trials were kept and used in the analyses.

\section{Overall reward and testing condition contrasts}

A mixed-effects ANOVA was carried out with reward condition as the within-subjects variable (with two levels, no-reward versus reward condition) and memory test type (spatial or temporal) as the between-subjects variable. Participants' accuracy during judgement of whether the grids presented to them were the same or different was measured as $d$ ' values. When analysed according to the face condition under which the grid was presented $(M=.24$, $S D=.57$ for neutral; $M=.30, S D=.66$ for smiling faces; figure $4 \mathrm{~A}$ ), differences in performance were not statistically significant $(F=.310, p=.580)$. However, the between-subjects mixedeffect ANOVA results showed that participants who took the version of the memory test with temporally manipulated grids scored significantly lower (neutral: $M=-.09, S D=.44$; smiling: $M=.10, S D=.53$ ) than those that completed the spatial version (neutral: $M=.57 ; S D=.48$; smiling: $M=.50 ; S D=.72$ ), when their accuracy (again, measured as $d$ 'values) was compared. When paired t-tests were carried out the results were $t(45)=4.90, p<.000$ for the neutral condition and $t(45)=2.16, p<.000$ for the smiling condition (figure $4 \mathrm{~B}$ ).

A similar mixed-effects ANOVA procedure was carried out for reaction times and confidence levels, and further t-tests were run when appropriate. Reaction times for answers in the testing phase were not significantly different for the neutral $(M=1737 \mathrm{~ms}, S D=777)$ versus smiling condition $(M=1743 \mathrm{~ms}, S D=781), t(45)=-.095, p=.925$. This was also true when the 
two testing test conditions were analysed separately, with paired t-tests yielding $t(23)=.364$, $p=.732$ for the temporal condition and $t(23)=-.343, p=.735$ for the spatial condition. Participants were not faster in the spatial versus temporal version of the discrimination task, as no between-subjects effects were observed in the mixed-effects ANOVA output, $F=.529, p=$ .471 (figure 4C).

Confidence levels during the discrimination task did not differ, overall, according to the encoding condition (neutral: $M=3.44, S D=.47$, smiling: $M=3.47, S D=.43$ ) relative to the events to be recognized, as a paired t-test produced the following output: $t(45)=-.805, p=$ .425 . However, independent t-test analyses showed that there were significant differences in confidence levels between testing conditions for grids that were associated with smiling faces, with participants answering more confidently when they were taking the temporal version of the memory test $(M=3.60, S D=.38)$ compared to the spatial one $(M=3.33, S D=.45) t(44)=$ 2.30, $p=.026$. These differences were only a trend for events that appeared after neutral faces, (temporal: $M=3.56, S D=.48$; spatial: $M=3.31, S D=.44$ ), $t(44)=-.25, p=.075$ (figure 4D).
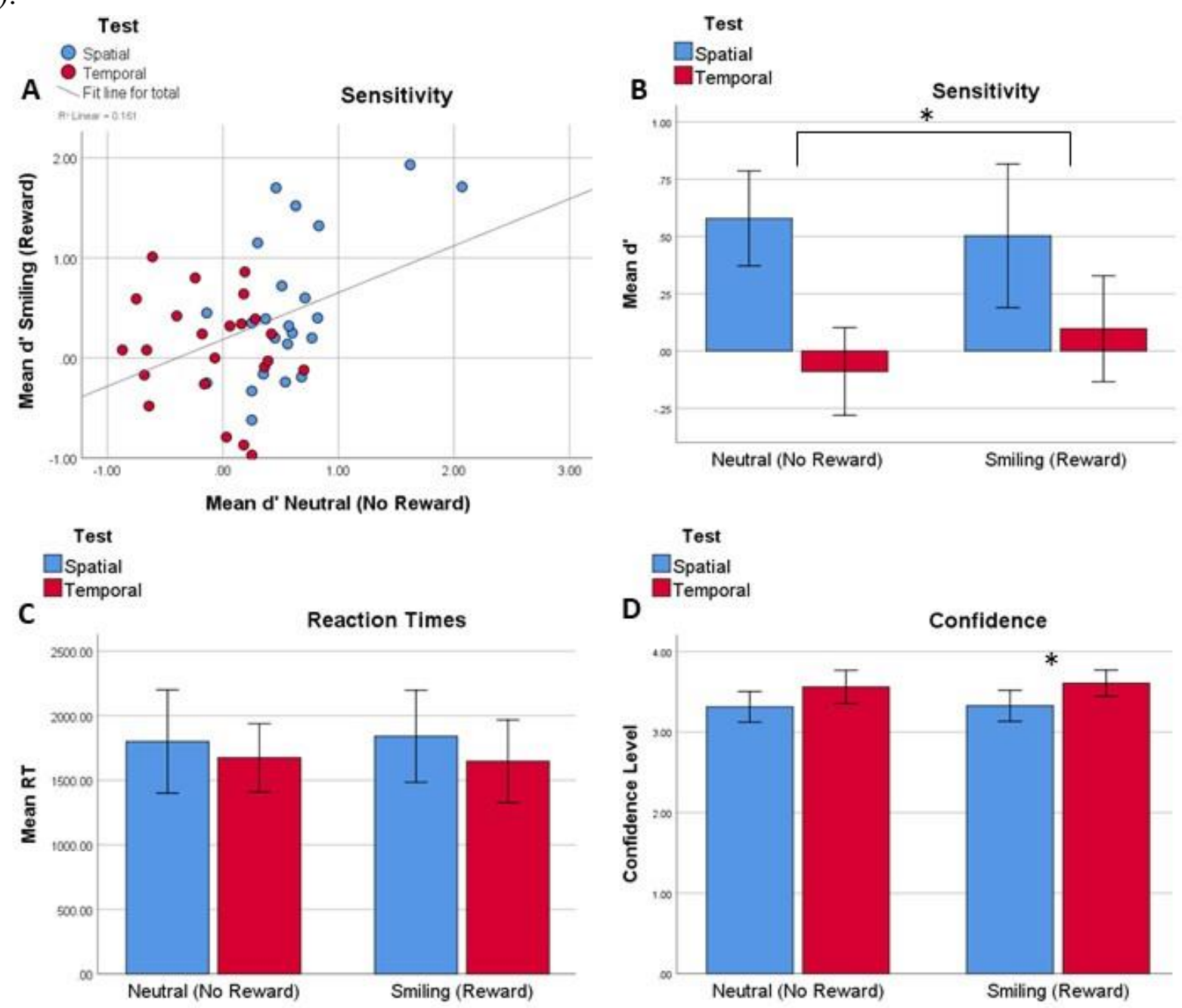

Figure 4. Performance during the discrimination task. Subject-by-subject $d$ ' values for both encoding conditions are plotted in (A) and colour-coded for test condition (blue for spatial, red for temporal). Mean $d$ 'values are summarized in (B); these did not change for within-subject variables but were significantly lower in the temporal versus spatial discrimination test $(p<.000)$ for both encoding conditions. Mean reaction times and confidence levels declared during the task are shown in (C) and (D), respectively. There were no significant withinor between-subjects differences for these latter sets of averages, except for the fact that confidence levels were higher for events associated with rewarding stimuli in the temporal version of the task, compared to the spatial one $(p=.026)$. All bars are colour-coded for the task version each participant completed, either spatial (blue) or temporal (red). Error bars show 95\% confidence intervals. 


\section{Mood-based reward condition contrasts}

PANAS scores were used to assign participants to either low or high positive and negative affect groups as described above (Methods, "Data analysis" section) and in Norlander et al. (2002). This resulted in the following distributions: 24 subjects belonged to the low positive affect group, 22 to the high positive affect subset; 26 participants had low negative affect scores and 20 were in the high negative affect group. Note that although both high positive affect scores and low negative scores indicate generally positive mood (and vice-versa for negative mood), membership to one group for the positive affect scale does not predict membership to either group for the negative affect scale. In fact, positive and negative affect scores were not correlated $(M=30.76, S D=5.39$ and $M=15.65, S D=5.03$, respectively), $r(45)$ $=-.161, p=.284$. A mixed-effects ANOVA was carried out with no-reward versus reward as the within-subjects condition, and affect score-based groups as the between-subjects condition. Separate two-way ANOVAs were performed for positive and negative affect groups. When analysing $d$ ' values by PANAS scores as categorical variables (either low or high), strong interactions between encoding condition and mood were observed for measures of positive, $F=$ $4.45, p=.041$ (figure 5A), but not negative affect, $F=.049, p=.825$ (figure 5B). Even stronger effects were present when positive affect $\mathrm{x}$ negative affect $\mathrm{x}$ encoding condition interactions were taken into account in a three-way mixed-effects ANOVA, $F=10.43, p=.002$. However, no effects of mood were observed when within-subjects differences were analysed separately based on whether participants were on the low or high end of the affective state spectrum.

A

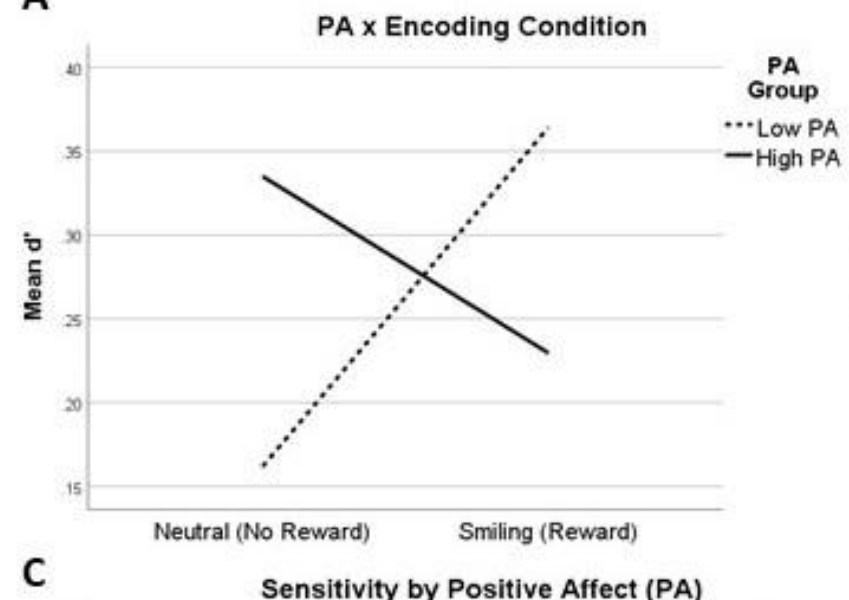

B

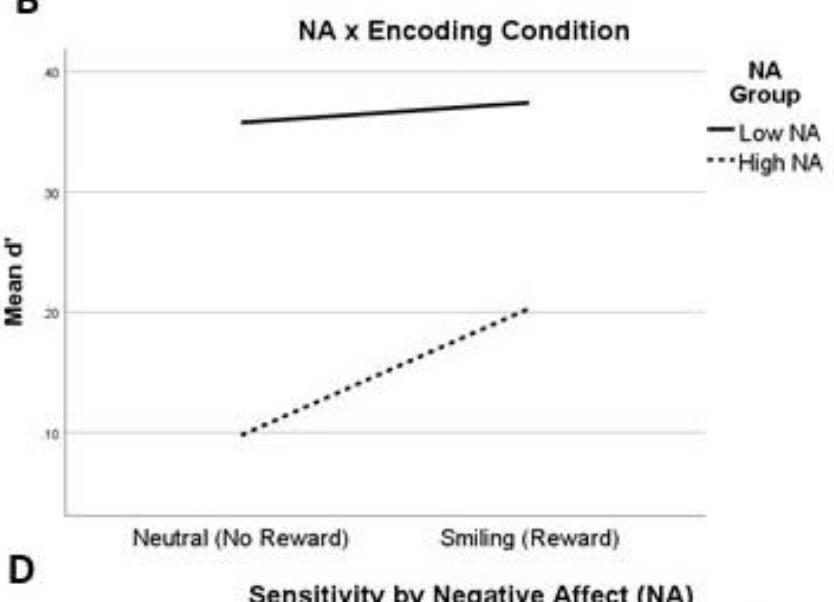

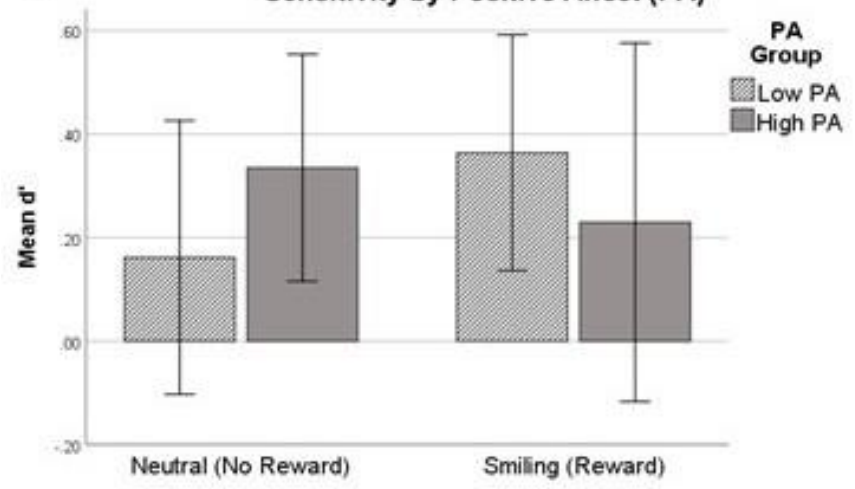

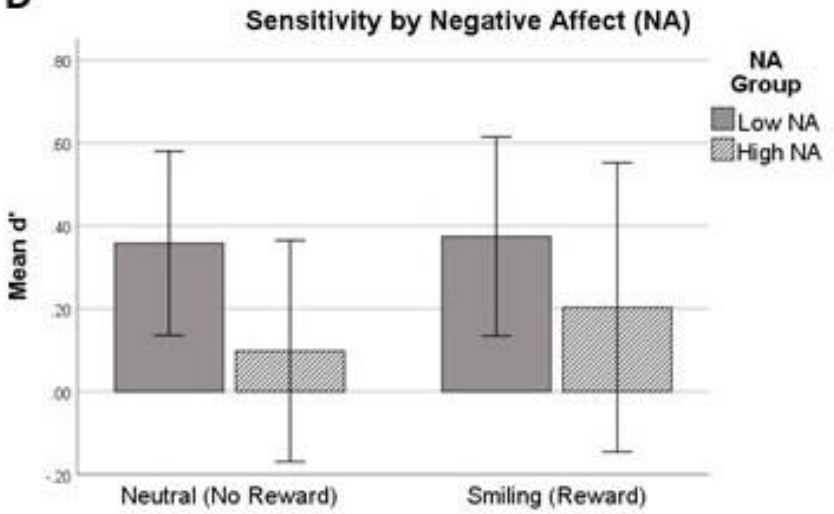

Figure 5. Interactions between mood and the effects of social reward on memory. When sensitivity ( $d$ ) was analysed according to positive affect (PA) scores - either high or low - significant PA x encoding condition interactions were observed $(p=.041)$; these are illustrated in the line graphs in $(\mathrm{A}) . d$ ' values were also grouped by encoding condition and membership to either the low NA or the high NA group. Although not statistically significant, NA $\mathrm{x}$ encoding condition interactions are illustrated in (B). (C) and (D) show subject-by-subject $d$ ' values for both encoding conditions, colour-coded according to which affect score subjects belonged to, with striped bars for either low positive affect (PA) or high negative affect (NA), and grey bars for either high PA or low NA. Error bars show 95\% confidence intervals. 
In fact, the results of a paired t-test analysis for the positive affect-based means were $t(23)=$ $1.56, p=.132$ for participants with low positive affect scores and $t(21)=-.224, p=.825$ for those in the high positive affect group (figure 5C). As for the negative affect-based analyses, results were $t(25)=-.133, p=.895$ and $t(19)=-.632, p=.535$ for the low and high negative affect, respectively (figure 5D). No between-subjects effects were observed.

When a small subset $(\mathrm{N}=11)$ of participants was selected, which had both low positive affect and high negative affect (relative to the group median), a significant effect of encoding condition on accuracy in the memory test was found $(M=-.12, S D=.43$ for the non-rewarded condition, and $M=.42, S D=.58$ for the rewarded condition), $t(10)=-2.99, p=.013$ (figure 6).

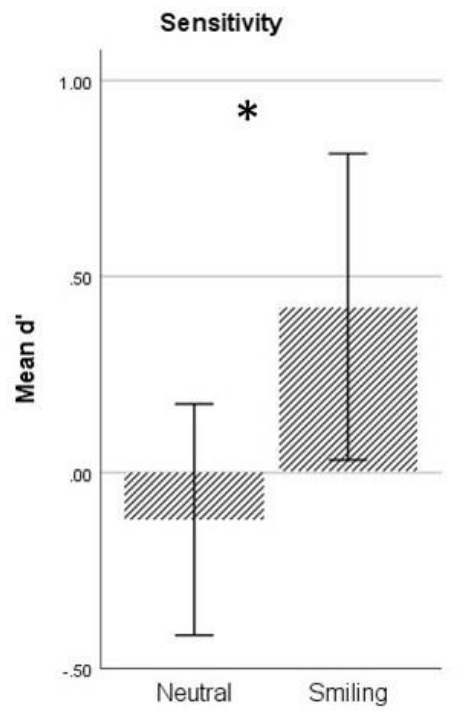

Figure 6. Performance during the discrimination task in a subset of very low-mood participants. Mean $d$ 'values for individuals with both low positive affect and negative affect scores $(\mathrm{N}=11)$ are illustrated separately for neutral (no reward) and smiling (reward) encoding conditions. Differences between the two means showed significant within-subjects differences $(p=.013)$. Error bars show $95 \%$ confidence intervals. 


\section{Discussion}

The main aim of the present experiment was to define the role of social rewards in modulating episodic memory We failed to support our leading hypothesis with data: participants scored similarly, and were not faster or slower, when attempting to recollect memories for events associated with neutral or rewarding stimuli. However, we found interesting interactions between PANAS scores and the encoding condition: participants that had low positive affect did show better scores for events associated with social rewards than for those that did not; for those who also scored highly on the negative affect scales, differences between the two means were statistically significant. Thus, current emotional states are crucial in defining the way in which rewards influence memory (as seen e.g. in Mayer et al., 1995). In addition, participants who took the test in which the temporal aspect was manipulated performed much worse than those for which spatial aspects changed, suggesting primacy for space-information encoding over temporal features (in line with Robin et al., 2018).

The observed differences between spatial and temporal encoding are discussed in the next section. It is obviously possible that we failed to observe an effect of social rewards on incidental episodic memory because there truly is not one or, at least, episodic memory for complex events fails to be enhanced when unrelated to rewards and their delivery. However, absence of evidence is not evidence of absence. Thus, some of the possible explanations for why this experiment failed to reject the main null hypothesis are provided in the following four following paragraphs. Finally, the role of mood in modulating the effect of rewards on memory is taken into account, as these considerations yielded the most interesting insights on the explored topic.

\section{Potential primacy of space relative to time in episodic memory}

When asked, most participants that had completed the spatial version of the memory test correctly reported noticing changes in the location of some of the objects on the grid. On the other hand, only one participant from the temporal manipulation group realized that detected changes on the grids were due to an inversion in the order of appearance of the relative pair of images; instead, most people attributed perceived changes to alterations in space, other features of the objects pair that, instead, were left unchanged. Consistently, memory performance - but not speed - was much worse for the temporal test condition, compared to the spatial one. This suggests that people prioritize the spatial aspects of events over the temporal ones, even though causality is typically inferred on the basis of both spatial (Scholl and Tremoulet, 2000) and temporal (Lagnado and Sloman, 2006) relationships. Indeed, the prominence of spatial features of events within episodic memory has been recently confirmed, at least to an extent, through an fMRI experiment (Robin et al., 2018). However, the authors did not include time-related features in their analyses. The hippocampus has repeatedly been proven crucial to episodic memory (Vargha-Khadem et al., 1997; Düzel al., 2001; Eichenbaum, 2001; but see Sharon et al., 2011). In particular, place cells encode both remembered and imaginary space, which are also activated whenever the spatial aspects of a memory are retrieved (Bird and Burgess, 2008). Instead, the role of the hippocampus in supporting temporal information is much more mysterious, although models exist that might explain it (Aimone et al., 2013; Nielson et al., 2015; Ekstrom and Ranganath, 2018). Furthermore, our perception of space is much more stable and rooted in our memories than that of time, which is instead processed much more flexibly. Interestingly, however, confidence levels for answers 
in the temporal test condition were significantly higher than those for the spatial manipulation, at least for grids associated with smiling faces. To quote Daniel Kahneman (2011), it seems that "the confidence that individuals have in their beliefs depends mostly on the quality of the story they can tell about what they see, even if they see little."

\section{Reward-related effort}

The brain differentiates rewards that are actively earned from those that are received passively. For instance, the caudate nucleus of the midbrain is only activated when there is contingency between reward and action, rather than reward per se (Tricomi et al., 2004). Dopamine signalling seems to be crucial in the detection of this coincidence (Martin-Soelch et al., 2001). Even though smiling faces are intrinsically rewarding to most people, their value might have not resulted in any behavioural change because they were not earned in any way, nor were participants intentionally seeking them (but see, for instance, Shore and Heerey, 2011; Sergerie et al. 2007). Neuroimaging experiments might provide an answer by checking for activation of reward-system areas (McClure et al., 2004).

\section{Reward anticipation versus receipt}

Even more important than whether an effort was made to obtain the reward, however, seems to be the presence of an anticipation phase during which the motivational relevance of the upcoming reward is calculated (Carter et al., 2009), and, as a result, other cognitive processes can be enhanced (Hickey et al., 2011; Anderson et al., 2011; Gruber et al., 2014; Murty and Adcock, 2014). In fact, anticipating a reward motivates an animal or human agent, puts them in a state of increased arousal and, consistently, it triggers increases in their levels of attention, cognitive control (in humans), and readiness to acquire new memories (as reviewed in Hidi, 2016). An anticipation period - which was lacking in our experiment - might thus be required for a reward to elicit effects on memory, at least when target items are not semantically related to the rewards themselves. Indeed, this is supported by neuroimaging reports for both motivated (Wittmann et al., 2005; Adcock et al., 2006) and incidental memorization (Gruber et al., 2014), which suggest that the observed effects are due to midbrain-hippocampus interactions active prior to target stimulus presentation, when reward cues appear (Adock et al., 2006; Shohamy and Adcock, 2010). Furthermore, areas of the brain's reward system, including the ventral striatum, are activated by the anticipation of both social and monetary rewards but not by their consumption (Rademacher et al., 2010), in line with findings on the role of dopamine in reward signalling (Schultz, 1998, 2007, 2016, and 2019). It is crucial, in fact, that in the occurrence of reward, two dopaminergic release bursts are triggered, one signifying the expected outcome during anticipation, and the other coding for the actual value of the reward obtained (Schultz, 1998). This allows calculating a prediction error - that is, expected reward plus or minus the outcome (Glimcher, 2011), in line with reinforcement learning models developed in the field of computer science (Sutton and Barto, 1998). Mather and Schoeke (2011) observed, by disentangling the role of each signal, that the actual outcome is what affects memory, rather than the expected reward. However, according to the authors, the critical effector seems to be outcome value relative to expectation, not in absolute terms. Similarly, Jang and colleagues (2019) found that prediction errors, and not overall rewards, increase incidental episodic memory. This could explain why, in some experimental settings, researchers failed to observe linear relationships between reward value and effects on memory (Wittmann et al., 2011; but see Bunzeck et al., 2010), even though monotonic increases in brain signals are seen for increasing reward values 
(Tobler et al., 2007; Cromwell and Schultz, 2003). Reward outcome is therefore important, but it is only half of the information.

Our findings support the idea that reward receipt alone does not induce a strong or appropriate enough dopaminergic release to influence hippocampal systems in such a way that memory for events occurring close to reward delivery would be enhanced simply due to such temporal vicinity. At the same time, extensive previous literature has shown how social cues do modulate memory when the tested features are intrinsic characteristics of the rewarding stimuli or for the context in which they are presented, even in the absence of, or regardless of, reward anticipation (Johansson et al., 2004; Kaufmann and Schweinberger 2004; Liu et al., 2008; Righi et al., 2015). It cannot be excluded that reward anticipation might be required to enhance memory for supposedly irrelevant information, but not for incidental learning of the context or characteristics of the rewarding stimulus itself. In order to find out whether social reward anticipation exerts different effects on episodic memory compared to its receipt, future studies could replicate the experimental paradigm presented here, but use a cue that predicts social reward before the event occurs instead of the first friendliness rating employed here, and only show smiling or neutral faces (the latter preceded by a different cue) after the incidental episode has been encoded.

\section{Neutral as negative and the inconsistent effects of arousal}

At least two further, yet opposing, potential instances ought to be considered. Both might be due to one potential issue in the present experiment, that is, that neutral facial expressions, rated as such independently, could have been perceived as negative during the course of the experiment, when they were contrasted with faces that were characterised by positive traits (Lee et al., 2008). Indeed, facial expressions are typically read and evaluated in context, rather than in isolation (Wieser et al., 2011; Wieser and Brosch, 2012). This possibility is supported by the fact that average friendliness judgments for supposedly neutral faces were shifted towards the negative end of the scale rather than being centred on it. It would be then relevant to note that some compelling evidence exists for negative emotional stimuli triggering memory benefits that are equivalent, if not superior, to those elicited by positive ones (Johansson et al., 2004, Murayama and Kitagami, 2013). Hence, both neutral and smiling faces might have elicited a positive effect on memory. Alternatively, but still assuming that neutral faces were perceived as negative, it could be that no net within-subjects effect was seen here on memory because, on the one hand, stimuli that were perceived as negative interfered with memory (Pratto and John, 1991; Fox et al., 2001; D'Argembeau and Van der Linden, 2011), and, on the other hand, smiling faces were distracting and thus similarly obstructive (Cromheeke and Muller, 2016; Beston et al., 2018).

Adding a third, more objectively aggressive or frightening condition - so that neutral faces would effectively be perceived as such by participants - would help explore the two just presented possibilities.

\section{Carryover effects}

We cannot exclude the possibility that the effects of social reward on memory were not only present, but they also lingered on, so as to exert positive modulation on memory for subsequent scenes associated with neutral stimuli (Mather and Schoeke, 2011; Murayama and Kitagami, 2013). This is also supported by neurobiological models, as increases in tonic firing persist over time and might thus blur the effects induced by rewards (Grace et al., 2007). Indeed, the fact that there was no attested difference in memory for events occurring after smiling or neutral faces might be explained by an overshadowing of the effects of social 
reward delivery on both. Introducing filler events to avoid carryover effects from previous trials might allow to control for this possibility (Anderson et al., 2006).

\section{Other design-related considerations}

The encoding paradigm used here was introduced for the first time with this and other studies taking place at the Russell lab. Perhaps, changing timings or showing participants scenes that more closely resembled real-world situations and relationships would have resulted in different findings. However, the effects of reward on memory might have simply been overstated in the past. Here, neutral scenes and an incidental kind of memory acquisition were deliberately chosen to explore the boundaries of such effects. Our findings suggest that reward-driven incidental memory enhancement might only occur for naturally salient stimuli, such as faces (Gruber et al., 2014), or in accordance with one's disposition. Indeed, social reward might also only be effective in specific subsets of the population, which is reflected by our results. This, specifically in relation to mood, is discussed in the next section.

\section{The effects of mood on socially relevant decisions and memory}

The value of a reward is far from being objective (Kable and Glimcher, 2007; Elliott et al., 2008; Knutson et al., 2008). Even across neurotypicals, differences in reward valuation have been reported to be explained by a number of individual-specific factors including, but not limited to, personality traits (Krebs et al., 2009), emotional state (Eldar and Niv, 2015; Young and Nusslock, 2016), reward-induced anxiety (Callan and Schweighofer, 2008), gender (Spreckelmeyer et al., 2009), age (Foulkes and Blakemore, 2016; Altikulaç et al., 2019; Durbin et al., 2019), functional brain connectivity (Smith et al., 2014), expectations (Koszegi and Rabin, 2006), loss and risk aversion (Kahneman and Tversky, 1979), hunger (Levy et al., 2013), cravings (Robinson and Berridge, 2013), stress (Porcelli et al., 2012), affective tendencies (Han et al., 2019), drug addiction (Hefner and Starr, 2017 ) and deprivation (Hefner et al., 2016) and intrinsic aspects of the reward to be obtained, such as physical effort required for, probability of obtaining, and delay of receipt of reward (Schultz, 2010; Seaman et al., 2018) or even comparisons with rewards obtained by others (Dal Monte et al., 2018). Such variables affect not only reward processing, but also reward-associated changes in other cognitive functions (Anderson et al., 2011; Berridge, 2012; Cromheeke and Mueller, 2016). In addition, all of these aspects are likely to interact and might even influence individuals in different ways, adding a further level of variability across individuals. Modulation for at least some of the factors mentioned here - e.g. personality traits (Chakrabarti et al., 2017) and social ability (Gossen, 2014; Hayward et al., 2018) - has been observed for social rewards, among other kinds of extrinsic recompenses. In addition, face processing is also influenced by current mood (Coupland et al., 2004; Adams et al., 2016); at the same time, expression identification can be predicted by positive and negative affect, even in the normal population (Voelkle, et al., 2014; Durbin et al., 2019). Therefore, it would seem reasonable that the subjective value of social rewards would be influenced by the current emotional state. For this reason, participants filled a mood questionnaire (PANAS; Watson et al, 1988) before they started the encoding section of our experiment. In fact, PANAS scores showed a strong interaction with condition (reward versus no reward) during encoding, with low positive affectindividuals showing improvement in the discrimination task when they had to judge events associated with smiling faces. These effects were significant for participants who had both low positive affect and high negative affect (see figure 6 above). The selection of participants according to these criteria yielded a small group of only 11 participants, and it would be incautious to draw conclusive inferences. However, given the significance of the result and the 
total number of participants $(\mathrm{N}=46)$, these results might well indicate the circumstances under which social rewards operate on episodic memory for neutral, incidentally acquired material. Future studies with bigger cohorts should be conducted to determine if these latter results could be truly representative of the whole population. It would also be interesting to gain perspectives on how social rewards impact other cognitive processes in people affected by certain affective disorders. In fact, depression is characterized both by a decrease in positive affect and an increase in negative affect (Nutt et al., 2007). As more attention is allocated to mood-congruent cues, depressed people overestimate the salience of negative stimuli (Leung et al., 2009). Consistently, sensitivity to social rewards is affected in patients with depression (He et al., 2019; Oumeziane et al., 2019). Neural responses to images of faces are also altered in depressed individuals (Victor et al., 2010), who are slower and less accurate than controls in recognizing neutral faces (Leppänen et al., 2004), and tend to interpret them as sad (Gollan et al., 2008). Note that most evidence points towards a mood-congruent enhancement of memory that should result in better recollection of negative events in depressed individuals (Gaddy and Ingram, 2014). This might seem to stand in opposition to our findings. However, it is still unknown how this bias affects incidentally encoded events. These and further considerations might help explain the results we observed for low-mood participants, even if our subjects had no diagnosis of any psychiatric or neurological condition. Future research is required to elucidate these aspects. 


\section{Conclusion}

Understanding the mechanisms through which memory can be enhanced by extrinsic incentives is important in teaching environments, everyday life, and can lead to strategies to improve performance in people with impaired memory (e.g., see Galli et al., 2018). We failed to observe an overall effect of social rewards on incidental episodic memory for neutral events. However, our experiment revealed strong interactions between the main outcome measure and participants' mood and drew attention to differences between the encoding of space- and time-related features. In addition, our results could be explained, for instance, by lack of a reward anticipation phase in our experimental design and by the fact that neutral faces might have been perceived as hostile once they were contrasted with smiling ones. Overall, the present study is a call for newer ones, as little is still known on the precise modalities of interaction between rewards and memory for events that occur in temporal proximity to them. 


\section{References}

Adams, R. B., Garrido, C. O., Albohn, D. N., Hess, U., Kleck, R. E. (2016). What facial appearance reveals over time: when perceived expressions in neutral faces reveal stable emotion dispositions. Frontiers in Psychology $7: 986$.

Adcock, R. A., Thangavel, A., Whitfield-Gabrieli, S., Knutson, B., Gabrieli, J. D. E. (2006). Reward-motivated learning: Mesolimbic activation precedes memory formation. Neuron 50:507-517.

Aimone, J. A., Iannaccone, L. R., Makowsky, M. D., Rubin, J. (2013). Endogenous group formation via unproductive costs. Review of Economic Studies 80(4):1215-1236.

Altikulaç, S., Bos, M. G. N., Foulkes, L., Crone, E. A., \& van Hoorn, J. (2019). Age and Gender Effects in Sensitivity to Social Rewards in Adolescents and Young Adults. Frontiers in Behavioral Neuroscience. 13:171.

Anderson, A. K., Wais, P. E., Gabrieli, J. D. E. (2006). Emotion enhances remembrance of neutral event past. PNAS 103:1599-1604.

Anderson, B. A., Laurent, P. A., Yantis, S. (2011). Value-driven attentional capture. Proceedings of the National Academy of Sciences USA 108:10367-10371.

Anderson, B. A., Laurent, P. A., Yantis, S. (2014). Value-driven attentional priority signals in human basal ganglia and visual cortex. Brain Research 1587:88-96.

Anderson, B. A. (2016). Social reward shapes attentional biases. Cognitive Neuroscience 7(1-4):30-36.

Anwyl-Irvine, A. L., Massonnié, J., Flitton, A., Kirkham, N., Evershed, J. K. (2020). Gorilla in our midst: An online behavioral experiment builder. Behavior Research Methods 52(1):388-407.

Baudonnat, M., Huber, A., David, V., Walton, M. E. (2013). Heads for learning, tails for memory: reward, reinforcement and a role of dopamine in determining behavioral relevance across multiple timescales. Front Neurosci 7:1-1.

Behrens, T. E., Hunt, L. T., Woolrich, M. W., Rushworth, M. F. (2008). Associative learning of social value. Nature 456(7219):245-249.

Berridge, K.C. (2012). From prediction error to incentive salience: mesolimbic computation of reward motivation. European Journal of Neuroscience 35(7)1124-1143.

Beston, P. J., Barbet, C., Heerey, E. A., Thierry, G. (2018). Social feedback interferes with implicit rule learning: Evidence from event-related brain potentials. Cognitive, Affective, \& Behavioral Neuroscience 18(6):1248-1258.

Bird, C. M., \& Burgess, N. (2008). The hippocampus and memory: insights from spatial processing. Nature Reviews Neuroscience 9(3):182-194.

Bliss, T. V., \& Collingridge, G. L. (1993). A synaptic model of memory: long-term potentiation in the hippocampus. Nature 361(6407):31-39.

Broadbent, N. J., Squire, L. R., Clark, R. E. (2004). Spatial memory, recognition memory, and the hippocampus. Proceedings of the National Academy of Sciences 101(40):14515-14520.

Bunzeck, N., Dayan, P., Dolan, R. J., Düzel, E. (2010). A common mechanism for adaptive scaling of reward and novelty. Human Brain Mapping 31(9):1380-1394.

Callan, D. E., \& Schweighofer, N. (2008). Positive and negative modulation of word learning by reward anticipation. Hum Brain Mapp 29:237-249.

Canli, T., Sivers, H., Whitfield, S. L., Gotlib, I. H., Gabrieli, J. D. (2002). Amygdala response to happy faces as a function of extraversion. Science 296(5576):2191-2191.

Carter, M. R., MacInnes, J. J., Huettel, S. A., \& Adcock, R. A. (2009). Activation in the VTA and nucleus accumbens increases in anticipation of both gains and losses. Frontiers in Behavioral Neuroscience 3(21):1-15.

Chakrabarti, B., Haffey, A., Canzano, L., Taylor, C. P., \& McSorley, E. (2017). Individual differences in responsivity to social rewards: Insights from two eye-tracking tasks. PloS One 12(10).

Chun, M. M., \& Turk-Browne, N. B. (2007). Interactions between attention and memory. Current Opinion in Neurobiology 17(2):177-184.

Cohen, M., Rissman, J., Suthana, N. A., Castel, A. D., Knowlton, B. J. (2015). Effects of aging on value-directed modulation of semantic network activity during verbal learning. Neuroimage 125:1046-1062. 
Coupland, N. J., Sustrik, R. A., Ting, P., Li, D., Hartfeil, M., Singh, A. J., Blair, R. J. (2004). Positive and negative affect differentially influence identification of facial emotions. Depression and Anxiety 19(1):31-34.

Cromheeke, S., \& Mueller, S. C. (2016). The power of a smile: stronger working memory effects for happy faces in adolescents compared to adults. Cognition and Emotion 30(2):288-301.

Cromwell, H. C., \& Schultz, W. (2003). Effects of expectations for different reward magnitudes on neuronal activity in primate striatum. Journal of Neurophysiology 89(5):2823-2838.

Dal Monte, O., Fan, S., Chang, S.W.C. (2018). Social subjective value in the primate midbrain. Nat Neurosci 21:1298-1299.

DeBruine, L., \& Jones, B. (2017). Face Research Lab London Set. [Photographs] Accessed online at https://figshare.com/articles/Face_Research_Lab_London_Set/5047666 on 13/01/2020.

Deci, E. L., \& Ryan, R. M. (2012). Motivation, personality, and development within embedded social contexts: An overview of Self-Determination Theory. In R.M. Ryan (Ed.), The Oxford handbook of human motivation (pp. 85111). New York: Oxford University Press.

Deci, E. L., \& Ryan, R. M. (2012). The Oxford Handbook of Human Motivation. Oxford: Oxford University Press.

Della Libera, C., \& Chelazzi, L. (2009). Learning to attend and to ignore is a matter of gains and losses. Psychological Science 20(6):778-784.

Dudai, Y., Carruthers, M. (2005). The Janus face of Mnemosyne. Nature 434:567

Dunbar, R. I. (1998). The social brain hypothesis. Evolutionary Anthropology: Issues, News, and Reviews 6(5):178190.

Dunsmoor, J. E., Murty, V. P., Davachi, L., Phelps, E. A. (2015). Emotional learning selectively and retroactively strengthens memories for related events. Nature 520(7547):345-348.

Durbin, K. A., Rastegar, S. \& Knight, B. G. (2019) Effects of age and mood on emotional face processing differ depending on the intensity of the facial expression, Aging, Neuropsychology, and Cognition, accessed online at https://doi.org/10.1080/13825585.2019.1700900 on 11/03/2020.

Düzel, E., Vargha-Khadem, F., Heinze, H. J., Mishkin, M. (2001). Brain activity evidence for recognition without recollection after early hippocampal damage. PNAS 98(14):8101-8106.

D'Argembeau, A., \& Van der Linden, M. (2004). Phenomenal characteristics associated with projecting oneself back into the past and forward into the future: Influence of valence and temporal distance. Consciousness and Cognition $13(4): 844-858$.

Eichenbaum, H. (2001). The hippocampus and declarative memory: cognitive mechanisms and neural codes. Behavioural Brain Research 127(1-2):199-207.

Ekstrom, A. D., \& Ranganath, C. (2018). Space, time, and episodic memory: The hippocampus is all over the cognitive map. Hippocampus 28(9):680-687.

Eldar, E., \& Niv, Y. (2015). Interaction between emotional state and learning underlies mood instability. Nat Commun 6:6149.

Elliott, R., Agnew, Z., Deakin, J. F. W. (2008). Medial orbitofrontal cortex codes relative rather than absolute value of financial rewards in humans. European Journal of Neuroscience 27: 2213-2218.

Fehr, E., \& Camerer, C. F. (2007). Social neuroeconomics: the neural circuitry of social preferences. Trends in Cognitive Sciences 11(10):419-427.

Fenker, D. B., Frey, J. U., Schuetze, H., Heipertz, D., Heinze, H. J., Düzel, E. (2008). Novel scenes improve recollection and recall of words. J Cogn Neurosci 20:1250-1265.

Foulkes, L., \& Blakemore, S. J. (2016). Is there heightened sensitivity to social reward in adolescence? Curr Opin Neurobiol 40:81-85.

Fox, E., Russo, R., Bowles, R., Dutton, K. (2001). Do threatening stimuli draw or hold visual attention in subclinical anxiety? Journal of Experimental Psychology: General 130(4):681.

Gable, P. A., \& Harmon-Jones, E. (2010). The effect of low versus high approach-motivated positive affect on memory for peripherally versus centrally presented information. Emotion 10(4):599.

Gaddy, M. A., \& Ingram, R. E. (2014). A meta-analytic review of mood-congruent implicit memory in depressed mood. Clinical psychology review 34(5):402-416. 
Galli, G., Sirota, M., Gruber, M. J., Ivanof, B. E., Ganesh, J., Materassi, M., Thorpe, A., Loaiza, V., Cappelletti, M. and Craik, F. I. (2018). Learning facts during aging: the benefits of curiosity. Experimental Aging Research 44(4):311-328.

Gershman, S. J., \& Daw, N. D. (2017). Reinforcement learning and episodic memory in humans and animals: an integrative framework. Annual Review of Psychology 68:101-128.

Glimcher, P. W. (2011). Understanding dopamine and reinforcement learning: the dopamine reward prediction error hypothesis. Proceedings of the National Academy of Sciences 108(Supplement 3):15647-15654.

Gollan, J. K., Pane, H. T., McCloskey, M. S., Coccaro, E. F. (2008). Identifying differences in biased affective information processing in major depression. Psychiatry Research 159(1-2):18-24.

Gossen, A., Groppe, S. E., Winkler, L., Kohls, G., Herrington, J., Schultz, R. T., Gründer, G. and Spreckelmeyer, K. N. (2014). Neural evidence for an association between social proficiency and sensitivity to social reward. Social Cognitive and Affective Neuroscience 9(5):661-670.

Grace, A. A., Floresco, S. B., Goto, Y., Lodge, D. J. (2007). Regulation of firing of dopaminergic neurons and control of goal-directed behaviors. Trends in Neurosciences 30(5):220-227.

Grace, A. A. (1991). Phasic versus tonic dopamine release and the modulation of dopamine system responsivity: a hypothesis for the etiology of schizophrenia. Neuroscience 41(1):1-24.

Gruber J.M., Gelman D.B., Ranganath C. (2014). States of curiosity modulate hippocampus-dependent learning via the dopaminergic circuit. Neuron 84(2):486-496.

Han, G. T., Tomarken, A. J., Gotham, K. O. (2019). Social and nonsocial reward moderate the relation between autism symptoms and loneliness in adults with ASD, depression, and controls. Autism Research 12(6):884-896.

Harari, Y. N. (2014). Sapiens: A brief history of humankind. New York, NY: Penguin Random House.

Hayward, D. A., Pereira, E. J., Otto, A. R., Ristic, J. (2018). Smile! Social reward drives attention. Journal of Experimental Psychology: Human Perception and Performance 44(2):206.

He, Z., Zhang, D., Muhlert, N., Elliott, R. (2019). Neural substrates for anticipation and consumption of social and monetary incentives in depression. Social Cognitive and Affective Neuroscience 14(8):815-826.

Hebb, D. O. (1949). The Organization of Behavior: A Neuropsychological Theory. Hoboken, NJ: John Wiley and Sons, Inc.

Heerey, E. A. (2014). Learning from social rewards predicts individual differences in self-reported social ability. Journal of Experimental Psychology: General 143(1):332.

Hefner, K. R., \& Starr, M. J. (2017). Altered subjective reward valuation among female heavy marijuana users. Exp Clin Psychopharmacol 25(1):1-12.

Hefner, K. R., Starr, M. J., Curtin, J. J. (2016). Altered subjective reward valuation among drug-deprived heavy marijuana users: Aversion to uncertainty. Journal of Abnormal Psychology 125(1):138-150.

Hickey, C., Chelazzi, L., Theeuwes, J. (2011). Reward has a residual impact on target selection in visual search, but not on the suppression of distractors. Visual Cognition 19(1):117-128.

Hidi, S. (2016). Revisiting the role of rewards in motivation and learning: Implications of neuroscientific research. Educational Psychology Review 28(1):61-93.

Huang, Y.Y., Kandel, E. R. (1995). D1/D5 receptor agonists induce a protein synthesis-dependent late potentiation in the CA1 region of the hippocampus. Proc Natl Acad Sci 92: 2446-2450.

Izuma, K., Saito, D. N., Sadato, N. (2008). Processing of social and monetary rewards in the human striatum. Neuron 58(2):284-294.

Jang, A. I., Nassar, M. R., Dillon, D. G., Frank, M. J. (2019). Positive reward prediction errors during decisionmaking strengthen memory encoding. Nature Human Behaviour 3(7):719-732.

Johansson, M., Mecklinger, A., Treese, A. C. (2004). Recognition memory for emotional and neutral faces: An eventrelated potential study. Journal of Cognitive Neuroscience 16(10):1840-1853.

Johnston, L., Miles, L., Macrae, C. N. (2010). Why are you smiling at me? Social functions of enjoyment and nonenjoyment smiles. British Journal of Social Psychology 49(1):107-127.

Kable, J., \& Glimcher, P. (2007). The neural correlates of subjective value during intertemporal choice. Nat Neurosci 10:1625-1633. 
Kahneman, D. (2011) Thinking, Fast and Slow. New York: Farrar, Straus and Giroux.

Kampe, K. K., Frith, C. D., Dolan, R. J., Frith, U. (2001). Reward value of attractiveness and gaze. Nature 413(6856):589-589.

Kang, M. J., Hsu, M., Krajbich, I. M., Loewenstein, G., McClure, S. M., Wang, J. T., Camerer, C. F. (2009). The wick in the candle of learning: Epistemic curiosity activates reward circuitry and enhances memory. Psychological Science 20:963-973.

Kaufmann, J. M., \& Schweinberger, S. R. (2004). Expression influences the recognition of familiar faces. Perception 33(4):399-408.

Kennedy, P.J., \& Shapiro, M.L. (2009). Motivational states activate distinct hippocampal representations to guide goal-directed behaviors. Proc Natl Acad Sci USA 106:10805-10810.

Kim, S. (2013). Neuroscientific model of motivational process. Frontiers in Psychology special section p1.

Knutson, B., Delgado, M. R., Phillips, P. E. M. (2008). Representation of subjective value in the striatum. In P. W. Glimcher, C. F. Camerer, E. Fehr, \& R. A. Poldrack (Eds.), Neuroeconomics: Decision making and the brain (pp. 389-406). New York: Academic Press.

Knutson, B. (1996). Facial expressions of emotion influence interpersonal trait inferences. Journal of Nonverbal Behavior 20(3):165-182.

Koszegi, B., \& Rabin, M. (2006). A model of reference-dependent preferences. Q J Econ 121:1133-1165.

Krach S., Paulus F.M., Bodden M., Kircher T. (2010) The rewarding nature of social interactions. Front Behav Neurosci 4:22.

Krebs, R. M., Heipertz, D., Schuetze, H., Düzel, E. (2011). Novelty increases the mesolimbic functional connectivity of the substantia nigra/ventral tegmental area (SN/VTA) during reward anticipation: evidence from high-resolution fMRI. Neuroimage 58(2):647-655.

Krebs, R. M., Schott, B. H., Düzel, E. (2009). Personality traits are differentially associated with patterns of reward and novelty processing in the human substantia nigra/ventral tegmental area. Biological Psychiatry 65:103-110.

Kringelbach, M. L., \& Rolls, E. T. (2003). Neural correlates of rapid reversal learning in a simple model of human social interaction. Neuroimage 20(2):1371-1383.

Lagnado, D. A., \& Sloman, S. A. (2006). Time as a guide to cause. Journal of Experimental Psychology: Learning, Memory, and Cognition 32(3):451-460.

Lansink, C. S., Goltstein, P. M., Lankelma, J. V., McNaughton, B. L., Pennartz, C. M. (2009). Hippocampus leads ventral striatum in replay of place-reward information. PLoS Biology 7(8).

Lashley, K. S. In search of the engram. (1950). In Symposium of the society for experimental biology (Vol. 4). New York, NY: Cambridge University Press.

Lee, E. Kang, J. I., Park, I. H. Kim, J. J., An, S. K. (2008). Is a neutral face really evaluated as being emotionally neutral? Psychiatry Research 157(1-3):77-85.

Lee, W., \& Reeve, J. (2013). Self-determined, but not non-self-determined, motivation predicts activations in the anterior insular cortex: an fMRI study of personal agency. Social Cognitive and Affective Neuroscience 8(5):538545 .

Lee, W., Reeve, J., Xue, Y., Xiong, J. (2012). Neural differences between intrinsic reasons for doing versus extrinsic reasons for doing: An fMRI study. Neuroscience Research 73(1):68-72.

Lemon. N., \& Manahan-Vaughan, D. (2006). Dopamine D1/D5 receptors gate the acquisition of novel information through hippocampal long-term potentiation and long-term depression. J Neurosci 26:7723-7729.

Lengyel, M., \& Dayan, P. (2008). Hippocampal contributions to control: the third way. Advances in Neural Information Processing Systems 20:889-896.

Levy D. J., Thavikulwat A. C., Glimcher, P. W. (2013). State dependent valuation: the effect of deprivation on risk preferences. PLoS One 8(1):e53978.

Linke, J., Kirsch, P., King, A. V., Gass, A., Hennerici, M. G., Bongers, A., Wessa, M. (2010). Motivational orientation modulates the neural response to reward. NeuroImage 49:2618-2625.

Leppänen, J. M., Milders, M., Bell, J. S., Terriere, E., Hietanen, J. K. (2004). Depression biases the recognition of emotionally neutral faces. Psychiatry Research 128(2):123-133. 
Lisman, J. E., Grace, A.A., Düzel, E. (2011). A neoHebbian framework for episodic memory; role of dopaminedependent late LTP. Trends Neurosci 34:536-547.

Lisman, J. E., \& Grace, A. A. (2005). The hippocampal-VTA loop: Controlling the entry of information into longterm memory. Neuron 46:703-713.

Liu, D. L. J., Graham S., Zorawski M. (2008) Enhanced selective memory consolidation following post-learning pleasant and aversive arousal. Neurobiology of Learning and Memory 89(1):36-46.

Liu, J., Harris, A., Kanwisher, N. (2002). Stages of processing in face perception: an MEG study. Nature Neuroscience 5(9):910-916.

Lundqvist, D., Flykt, A., Öhman, A. (1998). The Karolinska Directed Emotional Faces - KDEF. [Photographs] Accessed online at https://kdef.se/download-2/index.html on 13/01/2020.

Mahr, J. B., \& Csibra, G. (2018). Why do we remember? The communicative function of episodic memory. Behavioral and Brain Sciences 41.

Martin-Soelch, C., Leenders, K. L., Chevalley, A. F., Missimer, J., Künig, G., Magyar, S., Mino, A., Schultz, W. (2001). Reward mechanisms in the brain and their role in dependence: evidence from neurophysiological and neuroimaging studies. Brain Research Reviews, 36(2-3):139-149.

Marvin, C. B., \& Shohamy, D. (2016). Curiosity and reward: Valence predicts choice and information prediction errors enhance learning. Journal of Experimental Psychology: General 145(3):266.

Mason, A., Lorimer, A., Farrell, S. (2019). Expected value of reward predicts episodic memory for incidentally learnt reward-item associations. Collabra: Psychology 5(1).

Mather, M., \& Schoeke, A. (2011). Positive outcomes enhance incidental learning for both younger and older adults. Frontiers in Neuroscience 5:129.

Mather, M., \& Sutherland, M. R. (2011). Arousal-biased competition in perception and memory. Perspectives on Psychological Science 6(2):114-133.

Mayer, J. D., McCormick, L. J., Strong, S. E. (1995). Mood-congruent memory and natural mood: New evidence. Personality and Social Psychology Bulletin 21(7):736-746.

Mayes, L. C., Magidson, J., Lejuez, C. W., Nicholls, S. S. (2009). Social relationships as primary rewards: The neurobiology of attachment. In de Haan, M. \& Gunnar, M. R. (Eds.), Handbook of developmental social neuroscience (pp. 342-377). New York, NY: The Guilford Press.

McClure, S. M., York, M. K., Montague, P. R. (2004). The neural substrates of reward processing in humans: The modern role of fMRI. Neuroscientist 10:260-268.

McKone, E., Kanwisher, N., Duchaine, B.C. (2007). Can generic expertise explain special processing for faces? Trends in Cognitive Sciences 11(1).8-15.

Miendlarzewska, E. A., Bavelier, D., Schwartz, S. (2016). Influence of reward motivation on human declarative memory. Neuroscience and Biobehavioral Reviews 61:156-176.

Morris, J. S., Frith, C. D., Perrett, D. I., Rowland, D., Young, A. W., Calder, A. J., Dolan, R. J. (1996). A differential neural response in the human amygdala to fearful and happy facial expressions. Nature 383(6603):812-815.

Murayama, K., \& Kitagami, S. (2013). Consolidation power of extrinsic rewards: reward cues enhance long-term memory for irrelevant past events. Journal of Experimental Psychology: General 1(3).

Murayama, K., \& Kuhbandner, C. (2011). Money enhances memory consolidation-But only for boring material. Cognition 119(1):120-124.

Murty, V. P., \& Adcock, R. A. (2014). Enriched encoding: reward motivation organizes cortical networks for hippocampal detection of unexpected events. Cerebral Cortex 24(8):2160-2168.

Nielson, D. M., Smith, T. A., Sreekumar, V., Dennis, S., Sederberg, P. B. (2015). Human hippocampus represents space and time during retrieval of real-world memories. PNAS. 112(35):11078-11083.

Norlander, T., Bood, S. Å., and Archer, T. (2002). Performance during stress: affective personality, age, and regularity of physical exercise. Soc Behav Pers 30:495-508.

Nutt, D., Demyttenaere, K., Janka, Z., Aarre, T., Bourin, M., Canonico, P. L., Carrasco, J. L. and Stahl, S. (2007). The other face of depression, reduced positive affect: the role of catecholamines in causation and cure. Journal of Psychopharmacology 21(5):461-471. 
Oto, E. (n.d.). Brain, coronal section. [Digital image] accessed online at https://www.sciencesource.com/CS.aspx?VP3=SearchResult\&ITEMID=SS2543943\#/SearchResult\&ITEMID=SS254 $\underline{3943}$ on $21 / 04 / 2020$

Oumeziane, B. A., Jones, O., Foti, D. (2019). Neural sensitivity to social and monetary reward in depression: Clarifying general and domain-specific deficits. Frontiers in Behavioral Neuroscience 13.

O’Doherty, J., Winston, J., Critchley, H., Perrett, D., Burt, D. M., Dolan, R. J. (2003). Beauty in a smile: the role of medial orbitofrontal cortex in facial attractiveness. Neuropsychologia 41(2):147-155.

Phelps, E. A., Ling, S., and Carrasco, M. (2006). Emotion facilitates perception and potentiates the perceptual benefits of attention. Psychol Sci 17:292-299.

Porcelli, A. J., Lewis, A. H., Delgado, M. R. (2012). Acute stress influences neural circuits of reward processing. Front Neurosci 6:157.

Pratto, F., and John, O. (1991). Automatic vigilance: the attention-grabbing power of negative social information. J Pers Soc Psychol 61:380-391.

Rademacher, L., Krach, S., Kohls, G., Irmak, A., Gründer, G., Spreckelmeyer, K. N. (2010). Dissociation of neural networks for anticipation and consumption of monetary and social rewards. Neuroimage 49(4):3276-3285.

Rasch, B., \& Born, J. (2013). About sleep's role in memory. Physiological Reviews 93(2):681-766.

Righi, S., Gronchi, G., Marzi, T., Rebai, M., Viggiano, M. P. (2015). You are that smiling guy I met at the party! Socially positive signals foster memory for identities and contexts. Acta Psychologica 159:1-7.

Robin, J., Buchsbaum, B. R., Moscovitch, M. (2018). The primacy of spatial context in the neural representation of events. Journal of Neuroscience 38(11):2755-2765.

Robinson, M. J. F., \& Berridge, K. C. (2013). Instant transformation of learned repulsion into motivational "wanting". Curr Biol 23, 282-289.

Sajikumar, S., \& Frey, J.U. (2004). Late-associativity, synaptic tagging, and the role of dopamine during LTP and LTD. Neurobiol Learn Mem 82: 12-25.

Schmid, P. C., \& Mast, M. S. (2010). Mood effects on emotion recognition. Motivation and Emotion 34(3):288-292.

Scholl, B. J., \& Tremoulet, P. D. (2000). "Perceptual causality and animacy". Trends in Cognitive Sciences 4 (8):299-309.

Schultz, W. (1998). Predictive reward signal of dopamine neurons. J Neurophysiol 80:1-27.

Schultz, W. (2007). Reward. Scholarpedia 2(3):1652.

Schultz, W. (2010) Subjective neuronal coding of reward: temporal value discounting and risk. European Journal of Neuroscience 31: 2124-2135.

Schultz, W. (2016). Dopamine reward prediction-error signalling: a two-component response. Nat Rev Neurosci 17(3):183-95.

Schultz, W. (2019). Recent advances in understanding the role of phasic dopamine activity. F1000Research 8(F1000 Faculty Rev):1680, accessed online at https:/f1000research.com/articles/8-1680/v1 on 11/03/2020

Seaman, K. L., Brooks, N., Karrer, T. M., Castrellon, J. J., Perkins, S. F., Dang, L. C., Hsu, M., Zald, D. H., Samanez-Larkin, G.R. (2018). Subjective value representations during effort, probability and time discounting across adulthood. Social Cognitive and Affective Neuroscience 13(5):449-459.

Sergerie, K., Lepage, M., Armony, J. L. (2005). A face to remember: emotional expression modulates prefrontal activity during memory formation. Neuroimage 24(2):580-585.

Sharon, T., Moscovitch, M., Gilboa, A. (2011). Rapid neocortical acquisition of long-term arbitrary associations independent of the hippocampus. PNAS 108(3)1146-1151

Sharot, T., \& Phelps, E. A. (2004). How arousal modulates memory: Disentangling the effects of attention and retention. Cognitive, Affective, and Behavioral Neuroscience 4(3):294-306.

Sharot, T., \& Sunstein, C. R. (2020). How people decide what they want to know. Nature Human Behaviour 4:1419.

Shohamy, D., Adcock, R. A. (2010). Dopamine and adaptive memory. Trends Cogn Sci 14:464-472.

Shore, D. M., \& Heerey, E. A. (2011). The value of genuine and polite smiles. Emotion 11(1):169. 
Singer, A. C., \& Frank, L. M. (2009). Rewarded outcomes enhance reactivation of experience in the hippocampus. Neuron 64(6):910-921.

Skinner, B. F. (1938). The behavior of organisms. New York, NY: Appleton-Century-Crofts.

Smith, D. V., Clithero, J. A., Boltuck, S. E., Huettel, S. A. (2014). Functional connectivity with ventromedial prefrontal cortex reflects subjective value for social rewards. Social Cognitive and Affective Neuroscience 9(12):2017-2025.

Spaniol, J., Schain, C., Bowen, H. J. (2014). Reward-enhanced memory in younger and older adults. Journals of Gerontology Series B: Psychological Sciences and Social Sciences 69(5):730-740.

Spreckelmeyer, K. N., Krach, S., Kohls, G., Rademacher, L., Irmak, A., Konrad, K., Kircher, T., Grunder, G. (2009). Anticipation of monetary and social reward differently activates mesolimbic brain structures in men and women. Soc Cogn Affect Neurosci 4:158-165.

Squire, L. R., \& Zola-Morgan, S. (1991). The medial temporal lobe memory system. Science 253(5026):1380-1386.

Stark, C. E., \& Squire, L. R. (2003). Hippocampal damage equally impairs memory for single items and memory for conjunctions. Hippocampus 13(2):281-292.

Stickgold, R., \& Walker, M. P. (2013). Sleep-dependent memory triage: evolving generalization through selective processing. Nature Neuroscience 16(2):139.

Sutton, R. S., \& Barto, A. G. (1998). Introduction to reinforcement learning (Vol. 135). Cambridge, MA: MIT press.

Tambini, A., Rimmele, U., Phelps, E. A., Davachi, L. (2017). Emotional brain states carry over and enhance future memory formation. Nature Neuroscience 20(2):271.

Thorndike, E. L. (1898). Animal intelligence: an experimental study of the associative processes in animals. The Psychological Review: Monograph Supplements, 2(4):i.

Tobler, P. N., O'Doherty, J. P., Dolan, R. J., Schultz, W. (2007). Reward value coding distinct from risk attituderelated uncertainty coding in human reward systems. Journal of Neurophysiology 97(2):1621-1632.

Todd, R. M., Talmi, D., Schmitz, T. W., Susskind, J., Anderson, A. K. (2012). Psychophysical and neural evidence for emotion-enhanced perceptual vividness. Journal of Neuroscience 32(33):11201-11212.

Tricomi, E. M., Delgado, M. R. and Fiez, J. A., 2004. Modulation of caudate activity by action contingency. Neuron 41(2):281-292.

Tsukiura, T., \& Cabeza, R. (2011). Shared brain activity for aesthetic and moral judgments: implications for the Beauty-is-Good stereotype. Social Cognitive and Affective Neuroscience 6(1):138-148.

Tulving, E. (2002). Episodic memory: From mind to brain. Annual Review of Psychology 53(1):1-25.

Tulving, E. (2005). Episodic memory and autonoesis: Uniquely human? In Terrace, H.S. \& Metcalfe, J. (Eds.), The Missing Link in Cognition (pp. 4-56). NewYork, NY: Oxford University Press.

Valentine, T. (1991). A unified account of the effects of distinctiveness, inversion and race in face recognition. $Q J$ Exp Psychol 43(A):161-204.

Vargha-Khadem, F., Gadian, D. G., Watkins, K. E., Connelly, A., Van Paesschen, W., Mishkin, M. (1997). Differential effects of early hippocampal pathology on episodic and semantic memory. Science 277(5324):376-380.

Victor, T. A., Furey, M. L., Fromm, S. J., Öhman, A., Drevets, W. C. (2010). Relationship between amygdala responses to masked faces and mood state and treatment in major depressive disorder. Archives of General Psychiatry 67(11):1128-1138.

Voelkle, M. C., Ebner, N. C., Lindenberger, U., Riediger, M. (2014). A note on age differences in mood-congruent vs. mood-incongruent emotion processing in faces. Frontiers in Psychology 5:635.

Walter, H., Abler, B., Ciaramidaro, A., Erk, S. (2005). Motivating forces of human actions: Neuroimaging reward and social interaction. Brain Research Bulletin 67(5):368-381.

Watson, D., Clark, L. A., Tellegen, A. (1988). Development and validation of brief measures of positive and negative affect: the PANAS scales. Journal of Personality and Social Psychology 54(6):1063.

Wieser, M. J., \& Brosch, T. (2012). Faces in context: a review and systematization of contextual influences on affective face processing. Frontiers in Psychology 3:471.

Wieser, M. J., Gerdes, A. B., Büngel, I., Schwarz, K. A., Mühlberger, A., Pauli, P. (2014). Not so harmless anymore: How context impacts the perception and electrocortical processing of neutral faces. Neuroimage 92:74-82. 
Wittmann, B. C., Dolan, R. J., Düzel, E. (2011). Behavioral specifications of reward-associated long-term memory enhancement in humans. Learn Mem 18:296-300.

Wittmann, B. C., Schott, B. H., Guderian, S., Frey, J. U., Heinze, H. J., Düzel, E. (2005). Reward-related fMRI activation of dopaminergic midbrain is associated with enhanced hippocampus-dependent long-term memory formation. Neuron 45:459-467.

Young, C. B., Nusslock, R. (2016). Positive mood enhances reward-related neural activity. Social Cognitive and Affective Neuroscience 11(6):934-944.

Zajonc, R. B. (1965). Social facilitation. Science 149(3681):269-274. 